\title{
Characterizing Subsurface Hydraulic Heterogeneity of Alluvial Fan Using Riverstage Fluctuations
}

\author{
Yu-Li Wang ${ }^{1}$, Tian-Chyi Jim Yeh ${ }^{1,2}$, Jet-Chau Wen ${ }^{3,4, *}$, Shao-Yang Huang ${ }^{4}$, \\ Yuanyuan Zha ${ }^{5}$, Jui-Pin Tsai ${ }^{6}$, Yonghong Hao ${ }^{2}$, Yue Liang ${ }^{1,7}$ \\ 1. Department of Hydrology and Atmospheric Sciences, University of Arizona, \\ Tucson, Arizona, USA.
}

2. Key Laboratory for Water Environment and Resources, Tianjin Normal University, Tianjin, China.

3. Department of Safety, Health and Environmental Engineering, National Yunlin University of Science and Technology, Douliu, Yunlin, Taiwan.

4. Research Center for Soil and Water Resources and Natural Disaster Prevention, National Yunlin University of Science and Technology, Douliu, Yunlin, Taiwan.

5. State Key Laboratory of Water Resources and Hydropower Engineering Science, Wuhan University, Wuhan, China.

6. Department of the Civil Engineering, National Chiao-Tung University, Hsinchu, Taiwan.

7. National Engineering Research Center for Inland Waterway Regulation, Chongqing Jiaotong University, Chongqing, China.

* Corresponding Author

Professor Jet-Chau Wen wenjc@yuntech.edu.tw 


\section{ABSTRACT}

The objective of this study is to demonstrate the ability of riverstage tomography to estimate 2-D spatial distribution of hydraulic diffusivity $(D)$ of Zhuoshui River alluvial fan, Taiwan, using groundwater level data from 65 wells and stream stage data from 5 gauging stations. In order to accomplish this objective, wavelet analysis is first conducted to investigate the temporal characteristics of groundwater level, precipitation, and stream stage. The results of the analysis show that variations of groundwater level and stream stage are highly correlated over seasonal and annual periods while that between precipitation is less significant. Subsequently, spatial cross-correlation between seasonal variations of groundwater level and riverstage data is analyzed. It is found that the correlation contour map reflects the pattern of sediment distribution of the fan. This finding is further substantiated by the cross-correlation analysis using both noisy and noise-free groundwater and riverstage data of a synthetic aquifer, where aquifer heterogeneity is known exactly. The ability of riverstage tomography is then tested with these synthetic data sets to estimate $D$ distribution. Finally, the riverstage tomography is applied to the alluvial fan. The results of the application reveal that the apex and southeast of the alluvial fan are regions with relatively high $D$ and the $D$ values gradually decrease toward the shoreline of the fan. In addition, $D$ at northern alluvial fan is slightly larger than that at southern. These findings are consistent with the geologic evolution of this alluvial fan. 
Key words: River stage tomography, Hydraulic Tomography (HT), hydraulic

diffusivity (D). 


\section{INTRODUCTION}

For managing groundwater resources in a basin, information about hydraulic property distributions, which controls water and contaminant movement and their distributions in the basin, is essential. With this information, numerical surface water and groundwater models can be used for long-term management of water resources through estimation, prediction, and scenario analysis of surface water and groundwater systems.

Hydraulic tomography (HT) is a recently developed technique for characterizing subsurface heterogeneity. The rationale of HT is a joint interpretation of non-fully-redundant information about aquifer heterogeneity carried by drawdown fields induced from pumping tests at different locations. Specifically, successive pumping tests at different locations create different flow fields. Each flow field allows given observation wells to observe heterogeneity at certain parts of an aquifer at one perspective. Different flow fields thus facilitate viewing the heterogeneity at many different perspectives, using the same observation wells. HT can also include different types of information, such as observed head and flux [Zha et al., 2014; Tso et al., 2016], and prior geologic information such as layering [Tso et al., 2016; Zhao et al., 2016; Zhao and Illman, 2017]. It has been successively applied to small-scale synthetic aquifers [Hao et al., 2008; Yeh and Liu, 2000; Zhu and Yeh, 2005, 2006], laboratory sandboxes [Illman et al., 2007; Liu et al., 2002; Liu et al., 2007], plot-scale fields [Berg and Illman, 2011, 2013, 2015; Bohling et al., 2007; Cardiff et al., 2012; Huang et al., 2011; Li et al., 2007a; Straface et al., 2007; Vesselinov et al., 2001], and fractured granite field sites [Illman et al., 2009; Zha et al., 2014, 2015]. Its usefulness has been well documented by many studies. 
HT relies on artificial excitations such as pumping or injection of water. However, it is difficult or impractical to apply HT to basin-scale aquifer characterization because of ineffectiveness of artificial hydraulic tests for altering groundwater flow fields over kilometers or basin scales. Natural stimuli, such as atmospheric pressure variations [Rojstaczer, 1988], solid earth tides [Hsieh et al., 1988; Rojstaczer and Riley, 1990], ocean tides [Davis et al., 2000; Li et al., 2007b], precipitation [Jan et al., 2013], and even earthquake [Lin et al., 2004], are found to induce groundwater fluctuation from local to regional flow systems. For these reasons, Yeh et al. [2008] proposed utilizing natural stimuli as excitation sources for basin-scale hydraulic tomographic surveys.

River-stage tomography is a concept of extracting subsurface heterogeneity information from groundwater variation induced by changes in the river water level and migration of the flood wave from the upper to downstream. The time scale of variations could be event, seasonal, or even annual basis. Yeh et al. [2008 and 2009] explored this possibility of characterizing basin scale subsurface heterogeneity. They used a synthetic stream-aquifer system to demonstrate the potential of river-stage tomography utilizing event-based flood waves. Furthermore, recharge rates to groundwater aquifer from river through stream bed were simulated from Darcy’s flux and were utilized to represent the surface water/groundwater exchange in the work of Yeh et al. [2009]. This rate in the real world applications is unknown. Besides, groundwater level information recorded in a basin is likely influenced by many factors (such as precipitation, pumping, regional flow, and others). How to extract useful information from these data sets for characterizing basin-scale aquifer heterogeneity remains to be a challenge. For all these reasons, the applicability of the 
riverstage tomography for aquifer characterization in real world scenarios remains to be assessed.

While in this paper, interaction between surface water and groundwater is introduced by treating the river as a prescribed head boundary. This choice is due to the reason that the hydraulic conductivity $(K)$ of the stream bed usually is not available in the field dataset. As a result, the objective of this paper is to estimate basin-scale $D$ fields using stream induced groundwater level variations utilizing both synthetic and field data. In addition, the validity of treating the river as a prescribed head boundary on the hydraulic parameter estimation is discussed.

In order to achieve this goal, we first use wavelet analysis to analyze long-term precipitation, riverstage, and groundwater time series collected at the Zhuoshui River alluvial fan, Taiwan to select appropriate time span and data sets for spatial cross-correlation analysis. We compare the contour maps of the maximum cross-correlation and lag time between the riverstage and groundwater with the map of geology of the site to check the feasibility of the approach. We then use flow model to simulate groundwater level responses to the fluctuations of riverstage in a synthetic alluvial fan resembling the field site. The simulated groundwater responses and the riverstage information are then used to evaluate the performances of the cross-correlation and riverstage tomography analyses. The results from the noise-free and noise corrupted groundwater responses shed lights on the validity of those for the alluvial fan using field data, which may be influenced by many factors not considered. Afterward, the riverstage tomography is applied to estimate $D$ spatial distribution at the Zhuoshui River alluvial fan and the results are discussed.

\section{SITE DESCRIPTION}


The ideal candidate for the application of the river-stage tomography would be a groundwater basin that has been well instrumented and monitored. That is, the basin must have a large number of observation wells at different locations with screens opened at different depths and a sufficient number of river gauging stations. Most importantly, long term and high frequency (at least hourly) records of groundwater levels, riverstage, precipitation, and other hydro-meteorological processes over the basin are required. Few basins in the world meet this requirement because of costs associated with the operations and maintenances. The Zhuoshui River alluvial fan in Taiwan is uniquely qualified for this purpose because a massive amount of hydro-geological data has been collected since 1992 primarily for the purpose of irrigation groundwater management and earthquake investigations.

\subsection{Topography}

The Zhuoshui River alluvial fan (Figure 1a) is located at mid-west part of Taiwan. It is about $70 \mathrm{~km}$ long and $40 \mathrm{~km}$ wide and has an area of $1800 \mathrm{~km}^{2}$. It is bounded by Wu River at the north, Beigang River at the south, Taiwan Strait at the west, and the Central Mountain Range at the east. The Zhuoshui River cuts through the mountain pass of the ridge between Bagua Plateau and Douliu Hill at the center of the fan, and flows from east to west through the middle part of the fan and discharges into Taiwan Strait. The elevation of the fan is about $100 \mathrm{~m}$ at the apex and $0 \mathrm{~m}$ at the tail. The elevation drops from 100 to $30 \mathrm{~m}$ within $10 \mathrm{~km}$ after exiting the mountain pass between Bagua Plateau and Douliu Hill. Groundwater level is generally $30 \mathrm{~m}$ below the ground surface at the upper fan and $10 \mathrm{~m}$ below the ground at middle and tail.

\subsection{Geology}


The Central Geological Survey [1994, 1999] constructed 12 hydro-geological profiles for the alluvial fan based on the core samples from drilled wells. An unconfined and three confined aquifers, namely, layer 1 to layer 4, were approximately identified from shallow to 300 meters depth. The geological investigation indicated that all of the aquifers are connected to each other at apex of the fan where the deposition is mainly gravel (blue zones in Figure 1b). This alluvial fan consists of several layers of Holocene to Pleistocene sands and gravels, which form the three confined aquifers separated by marine mud [Central Geological Survey, 1994, 1999]. It suggested that the rising and falling of the mean sea levels caused by global climate change late in the Quaternary Period created the layered structure of the alluvial fan [Water Resources Agency, 2014]. Massive gravels and coarse sands, which comprise many layers of the upper fan, pinch out toward the west of the fan at shoreline, while the mud layers thicken. An interface between the gravels and the arenaceous sediments was identified that separates the partially confined and confined aquifers.

The distribution of sediments in the alluvial fan follows gravel, sand, and clay from the apex to the tail of the alluvial fan. This pattern agrees with the sedimentation process of the river that angular conglomerates and breccias tend to settle down at the headwater where transport energy is relatively high, while the arkose and finer materials such as silt and clay tend to be at the middle and tail of the river, which has low transport energy. Due to the drift of the flow path of Zhuoshui River in the past, the sediment profile at northern part of middle alluvial fan exhibits interlocked sand and silt/clay features. On the other hand, the southern part of the alluvial fan does not manifest such features. This is probably attributed to the fact that the sediment in the southern part was deposited by Beigang River, instead of Zhuoshui River, and the 
source of the sediment was from Douliu Hill. The region at the northern boundary of the alluvial fan near the Wu River and west foot of Bagua Plateau mainly consists of gravels. [Water Resources Agency, 2014]

\subsection{Hydrological Data Availability}

A groundwater monitoring network system was gradually established throughout the fan since 1992 and was expanded to the current size at 1997. The network consists of 74 evenly distributed groundwater stations, where 188 monitoring wells are installed at various depths ranging from 24 through $306 \mathrm{~m}$. Most of the wells are screened at only single depth, and the water levels at all of the wells have been recorded hourly since 1997. In this study, 65 monitoring wells are selected. All of them have screen intervals opened at the unconfined or partially confined aquifer. The partially confined aquifers mostly locate along the southern alluvial fan where mainly consists of silt/clay. Most screen intervals are opened at depth ranging from 8 to 103 m with screen length between 6 to $18 \mathrm{~m}$, while the others are from 50 to $300 \mathrm{~m}$ with screen length between 6 to $60 \mathrm{~m}$. There are 21 stream gauges along the rivers through the fan. Stream stage or flow rate utilized in this study are labeled in figure 1a. There are four stream gauging stations (namely, Zhangyun Bridge, Xizhou Bridge, Ziqiang Bridge, and Xibin Bridge) along the Zhuoshui River, located at the apex, middle, and the tail of the alluvial fan, respectively. Stream gauge (Dadu Bridge) at downstream of Wu River at northern boundary of the alluvial is also used in this study. Riverstage and flow rate have been recorded hourly. In addition, hourly meteorological data has been collected from about 50 weather stations since 2009. We select Xiashuipu weather station located at apex of the fan for the precipitation analysis. Daily 
precipitation records since 1997 recorded at Chiayi weather station, which located 40 km southern from the Zhuoshui River are analyzed.

\section{METHODS OF ANALYSES}

As mentioned previously, groundwater level fluctuations may reflect excitations from a large number of natural processes (precipitation, evapotranspiration, or earthquakes) or human activities (e.g., pumping and irrigation) at different time scales and frequencies, other than riverstage. To discriminate these various components in groundwater level signals is intractable because of the lack of data and knowledge of all processes. Instead, we use wavelet analysis to examine temporal variation of riverstage and groundwater data to select the most appropriate time where the relationships of the two are most significant. We then examine the spatial correlationship between riverstage and groundwater data at different parts of the fan. Afterward, we use successive linear estimator (SLE) algorithm and the riverstage and groundwater data to estimate hydraulic diffusivity $(D)$ distribution in the fan. This section briefly discusses the wavelet analysis, spatial cross-correlation analysis, and the SLE algorithm.

\subsection{Wavelet Analysis}

Many methods for analyzing time series, including Fourier transform, cosine and sine transform, and orthogonal polynomial expansion are available. Unlike these methods, time-frequency analysis methods such as wavelet transform could derive the instantaneous frequency. Similar to the Fourier transform, the wavelet transform measures the similarity between signal and analyzing function by using their inner product 


$$
C(a, b)=\frac{1}{\sqrt{b}} \int_{-\infty}^{\infty} f(t) \psi\left(\frac{t-a}{b}\right) d t \quad[1]
$$

where $f(t)$ is the time series of riverstage or groundwater data and the analyzing function is a mother wavelet $\psi\left(\frac{t-a}{b}\right) \cdot t[\mathrm{~T}]$ is time. The wavelet transform compares the signal with shifted and compressed or stretched the mother wavelet using location $a[\mathrm{~T}]$ and scaling $b$ [1/T] parameters. The resulting transform $C(a, b)$ is a function of location and scaling parameters called wavelet coefficient or wavelet amplitude spectrum. The square of wavelet coefficient could be seen as power spectrum, which indicates the relative energy distribution along different location and scale.

Because the mother wavelet is not an infinite sinusoid function, there is only an approximate answer for the relationship between the scale $b$ and frequency. In wavelet analysis, the way to relate the scale to frequency is to determine the center frequency $f_{c}[1 / \mathrm{T}]$ of the wavelet and use the following relationship

$$
f(a)=\frac{f_{c}}{b \Delta}[2]
$$

where $f(a)$ is the pseudo-frequency [1/T] corresponding to the scaling parameter while $\Delta$ is the sampling period [T]. The center frequency $f_{c}$ is the specific frequency that has the strongest amplitude or contributes the most energy to the construction of mother wavelet.

There are many mother wavelets such as Haar, Gaussian Morlet, Meyer, and Daubechies could be chosen [Misiti et al., 2007]. The rationale behind choosing the proper mother wavelet is using those which could best describe the characteristics (i.e., the sharp or smooth transitions between peak and trough) of the signal to be analyzed. 
In practices, one could take a trial and error approach to test the reconstructing performance of different wavelets. The similarity between the reconstructed and original signal gives some hint on how the given wavelet is capable of representing the signal. Here, we choose Mexican hat function because it best describes the original signal. Mexican hat function is the $2^{\text {nd }}$ order derivation of the Gaussian function.

$$
\psi(t)=\frac{2^{1.25}}{\sqrt{3}}\left(1-2 \pi t^{2}\right) \exp \left(-\pi t^{2}\right) \quad[3]
$$

The inverse wavelet transform is defined as

$$
\begin{aligned}
& f(t)=\frac{1}{C_{\psi}} \int_{0}^{\infty} \int_{-\infty}^{\infty} \frac{1}{b^{2.5}} C(a, b) \psi\left(\frac{t-a}{b}\right) d a d b \\
& C_{\psi}=\int_{-\infty}^{\infty} \frac{|\Psi(\omega)|^{2}}{|\omega|} d \omega<\infty \quad \text { [4.2] }
\end{aligned}
$$

where $\Psi(\omega)$ is the Fourier transform of $\psi\left(\frac{t-a}{b}\right)$ and $\omega[1 / \mathrm{T}]$ is frequency.

Wavelet coherence is a method identifying relationships between two signals in frequency as well as in time. Wavelet coherence is evaluated by magnitude-squared coherence, which is

$$
\operatorname{coh}(\omega, t)=\left[\frac{\sum_{i=1}^{N}\left(C_{i}(\omega)-\bar{C}\right)\left(H_{i}(\omega, L)-\bar{H}\right)^{*}}{\sqrt{\sum_{i=1}^{N}\left(C_{i}(\omega)-\bar{C}\right)\left(C_{i}(\omega)-\bar{C}\right)^{*} \sum_{i=1}^{N}\left(H_{i}(\omega, L)-\bar{H}\right)\left(H_{i}(\omega, L)-\bar{H}\right)^{*}}}\right]^{2}
$$

where $C$ and $H$ are wavelet coefficients of two signals, $\bar{C}$ and $\bar{H}$ are the average wavelet coefficients within the smoothing domain in time and frequency, $N$ is total number of sampling within the smoothing domain, and $L$ is time or phase lag. * denotes conjugate of the complex number. $\operatorname{coh}(\omega)$ could be any value ranging 
between 0 and 1 while 1 means the two signals at the certain time and frequency are perfectly correlated with certain lag of time and 0 means uncorrelated. Thus, it could be conceptualized as a localized correlation coefficient in the time and frequency domain. Notice that instead of Mexican hat, we utilize Morlet as the mother wavelet in the coherence analysis. The reason of choosing another mother wavelet is because the wavelet coefficient of Mexican hat does not have imaginary part while Morlet does. Without the imaginary part, the influence of phase lag (i.e., time lag) on the similarity among two signals could not be displayed. Here, we utilize MATLAB wcoherence function to conduct the coherence analysis.

\subsection{Spatial Cross-Correlation Analysis}

After identifying the time periods where the groundwater level data are highly correlated with those of the riverstage, correlation between riverstage at different gauging stations and groundwater fluctuation at each individual well is investigated by cross-correlation analysis. The cross-correlation is an index providing the similarity of two time series as a function of time lag of one relative to the other. It is evaluated using the following formula:

$$
\operatorname{Cor}(L)=\frac{\frac{1}{N-L} \sum_{i=1}^{N-L}[(h(i)-\bar{h})(g(i+L)-\bar{g})]}{\sqrt{\frac{1}{N} \sum_{i=1}^{N}(h(i)-\bar{h})^{2}} \sqrt{\frac{1}{N} \sum_{i=1}^{N}(g(i)-\bar{g})^{2}}}=\frac{\frac{1}{N-L} \sum_{i=1}^{N-L}[(h(i)-\bar{h})(g(i+L)-\bar{g})]}{\sigma_{h} \sigma_{g}} \text { [6] }
$$

where $\operatorname{Cor}(L)$ is the cross-correlation and $L[\mathrm{~T}]$ is time lag or sampling point lag; $h$ [L] and $g$ [L] represent time series of stream stage and groundwater level, respectively. $\bar{h}$ and $\bar{g}$ are the means, and $\sigma_{h}$ and $\sigma_{g}$ are the standard deviations of the corresponding time series. They are obtained using entire $\mathrm{N}^{\text {th }}$ number of data. $N$ is the total number of data in time series. 


\subsection{Successive Linear Estimator}

The goal of this study is to demonstrate the feasibility to utilize the groundwater variation in response to the riverstage change to characterize the hydraulic diffusivity of the alluvial fan. In order to accomplish this goal, a stochastic estimator (successive linear estimator, SLE, developed by Yeh and his colleague) is used. A brief description of the estimator is given below. Detailed discussion could be found at Yeh et al., 1996, Zhang and Yeh, 1997, and Zhu and Yeh, 2005.

Suppose we adopt a highly parameterized heterogeneous conceptual model for the fan and discretize the domain of the fan into $n$ elements. Suppose we have collected a total number of $m$ observed heads at wells in the fan in time and space, denoted by $\mathbf{h}^{*}(m \times 1)$. The estimation of parameter fields, given the observed heads, is iteratively determined using the following linear estimator:

$$
\hat{\mathbf{f}}^{(r+1)}=\hat{\mathbf{f}}^{(r)}+\boldsymbol{\omega}^{(r)}\left[\mathbf{h}^{*}-\mathbf{h}^{(r)}\right][7]
$$

Where $\hat{\mathbf{f}}^{(r)}$ is a $n \times 1$ vector, representing perturbations of the estimated $\ln D$ (i.e., the estimates minus the unconditional mean $\ln D$ ), and the superscript $r$ is the iteration index. $\mathbf{h}^{(r)}(m \times 1)$ is the simulated heads at the observation wells, based on the $\ln D$ estimated from previous iteration. If $D$ measurements are not available, $\hat{\mathbf{f}}^{(0)}$ is zero and the estimated $D$ is the unconditional mean $D$. On the other hand, if some $D$ measurements are available, one can use kriging to derive the conditional mean $D$ field and $\hat{\mathbf{f}}^{(0)}$ is then the perturbation of kriging estimates about the unconditional mean $D$ field.

In Eq. (7), the matrix $\boldsymbol{\omega}^{(r)}(n \times m)$ is the weight matrix, representing the contribution of the difference between the observed and simulated conditional heads 
(i.e., $\mathbf{h}^{*}$ and $\mathbf{h}^{(r)}$, respectively) to the improvements for the previous estimated $\ln D$. The matrix $\boldsymbol{\omega}^{(r)}$ is determined by solving the following equation:

$$
\boldsymbol{\omega}^{(r)} \boldsymbol{\varepsilon}_{h h}^{(r)}=\boldsymbol{\varepsilon}_{f h}^{(r)}[8]
$$

The matrix $\boldsymbol{\varepsilon}_{h h}^{(r)}(m \times m)$ is the conditional covariance of observed head while the matrix $\boldsymbol{\varepsilon}_{f h}^{(r)}(n \times m)$ is the conditional cross covariance between head and each element. They are evaluated using the first-order approximation. That is,

$$
\begin{aligned}
& \boldsymbol{\varepsilon}_{f h}^{(r)}=\boldsymbol{\varepsilon}_{f f}^{(r)} \mathbf{J}_{f h}^{(r)} \\
& \boldsymbol{\varepsilon}_{h h}^{(r)}=\mathbf{J}_{f h}^{(r) T} \boldsymbol{\varepsilon}_{f h}^{(r)}
\end{aligned}
$$

where $\mathbf{J}_{f h}^{(r)}(n \times m)$ is the sensitivity of head with respect to the change of parameter. The sensitivity matrix is evaluated using the adjoint state approach [ $\mathrm{Li}$ and Yeh, 1998; Li and Yeh, 1999; Lu and Vesselinov, 2015]. After completion of the linear estimation, the conditional residual covariance of $\hat{\mathbf{f}}^{(r+1)}$ is updated subsequently by

$$
\boldsymbol{\varepsilon}_{f f}^{(r+1)}=\boldsymbol{\varepsilon}_{f f}^{(r)}-\boldsymbol{\omega}^{(r)} \boldsymbol{\varepsilon}_{f h}^{(r) T} \quad[10]
$$

These steps are repeated successively to improve the estimate of $\hat{\mathbf{f}}^{(r)}$ for iteration $r \geqq 1$.

When solving Eq. 8, a dynamic stabilizer is added into it for the purpose of numeric stability. Furthermore, the measurement error could be considered as well. That is, Eq. (8) is rewritten as

$$
\boldsymbol{\omega}^{(r)}\left(\boldsymbol{\varepsilon}_{h h}^{(r)}+\mathbf{R}+\boldsymbol{\theta}^{(r)} \delta\right)=\boldsymbol{\varepsilon}_{f h}^{(r)}[11]
$$

where $\mathbf{R}(m \times m)$ is the covariance matrix of the measurement error and $\boldsymbol{\theta}^{(r)}$ $(1 \times m)$ is the dynamic stabilizer. Dynamic stabilizer is added to the diagonal elements of $\boldsymbol{\varepsilon}_{h h}^{(r)}$ ( $\delta$ is Dirac delta function) to stabilize the solution. This technique is also known as Levenberg-Marquardt Algorithm or damped least-squares, which hybrids 
the Gauss-Newton algorithm and the gradient descent to solve non-linear least squares problems. The reason why using the stabilizer term is that when the initial guess values are far away from the true solutions for a nonlinear problem, the Gauss-Newton solution (without stabilizer term) may lead to divergence if a full step is taken to update the parameters. The dynamic stabilizer could be the maximum value of the diagonal elements of $\boldsymbol{\varepsilon}_{h h}^{(r)}$ times a user-specified multiplier [Yeh et al., 1996] if the dimensions or orders of magnitude of observed data are identical. If the dimensions or orders of magnitude of observed data are different, then it is better to use the value of the diagonal elements of $\boldsymbol{\varepsilon}_{h h}^{(r)}$ times a user-specified multiplier as the dynamic stabilizer to insure the contribution from the small orders of magnitude observed data as well as the contribution from measurement with different dimensions [Zha et al., 2014].

At the beginning of the iteration, we need to specify the initial guessed values for the parameter field ( $\hat{\mathbf{f}}^{(0)}$ used in Eq. (7)) and covariance function ( $\boldsymbol{\varepsilon}_{f f}^{(0)}$ used in Eq. (9) and (10)). From the Bayesian perspective, it is reasonable to use the prior information, such as knowledge of mean and variance of the unknown parameter field, as initial guess. After that, the parameter field and the covariance will be updated iteratively due to gradual assimilation of observation information.

Two criteria, the mean absolute error ( $L_{1}$ norm) and the mean squared error ( $L_{2}$ norm) are used to evaluate the differences between observed head and simulated head:

$$
L_{1}=\frac{1}{m} \sum_{i=1}^{m}\left|\mathbf{h}_{i}^{*}-\mathbf{h}_{i}^{(r)}\right| \text { and } L_{2}=\frac{1}{m} \sum_{i=1}^{m}\left(\mathbf{h}_{i}^{*}-\mathbf{h}_{i}^{(r)}\right)^{2}
$$

\section{ANALYSES AND RESULTS}

\subsection{Temporal Analysis of Head, Riverstage, and Rainfall Data}


4.1.1. Periodicity Analysis. The daily time series and its associated wavelet spectrograms of groundwater levels at all available observation wells and river flow rate at Zhangyun Bridge during 1997 to 2013 are analyzed. It is observed that the groundwater level and river flow rate during 1997 to 2013 have significant periodic variations on annual period (figure 1c). The annual periodic cycle of the flow rate follows the meteorological characteristics of the area. That is, frequent precipitation during rainfall season from April to October leads to the increase in surface runoff and in turn, the stream discharge. The lack of rainfall during the winter and early spring leads to low flow rate of the river. The annual groundwater level variation, on the other hand, follows the trends of both agriculture water demand and meteorological characteristics. Generally, groundwater levels decrease at the first half portion of the growing season due to pumping and evapotranspiration, which begins from early spring until May, and afterward, the groundwater levels start to recover because of the rainfall season. The amount of recovery depends on recharge from rainfall and groundwater withdraw.

Two selected wells, Tan-Cian (1-1), Si-Hu (1) (labeled with square in figure 1a), located at about 1 and 15 kilometers, respectively, away from the river are utilized to illustrate the relationship between the groundwater level variations within the alluvial fan and the riverstage as well as precipitation. The reasons for choosing these two wells are that Tan-Cian is the nearest well to the stream, while Si-Hu is located almost at the center of the northern alluvial fan.

Hourly water levels during 2010 are selected as the example to investigate the higher frequency signals. Figure 2a, 2b, and 2c illustrate the hourly time series and its associated wavelet spectrograms of groundwater level at Tan-Cian (1-1), Si-Hu (1), and stream stage at Ziqiang Bridge, respectively. It can be observed that as the 
distance between monitoring well and riverstage measurement location becomes further apart, the groundwater level hydrograph becomes smoother and oscillates less. The phenomenon that higher frequency groundwater level fluctuations are filtered by the aquifer is presented in wavelet spectrogram as well. Compared spectrograms between Tan-Cian (1-1) and Si-Hu (1), amplitude spectrums of high frequency signals at further well are less than the closer one.

In addition, during the rainfall season (i.e., April to October: 100 to 300 on the horizontal time axis), by taking a glance through these time series, it seems that there are some periodic groundwater level and stream stage peaks and troughs, although they are not obvious. On the other hand, the groundwater level and stream stage during the rest of the day are flat. To better explore the temporal periodic variations quantitatively, we relate the time series to wavelet spectrograms. It is observed in spectrograms at Tan-Cian (1-1) and Si-Hu (1) that there are some positive-negative (i.e., the warmer-cooler color) amplitude spectrum pairs with period around 60 to 80 days from day 100 to 300 (i.e., region surrounded by black dash line in figure 2). Relating these positive-negative pairs to the groundwater level variation, we can find that the positive amplitude spectrums are corresponding to the rising of water level while the negative are corresponding to the falling. Based on the relation between spectrogram and physical significance, we then can infer that the groundwater level at Tan-Cian (1-1) and Si-Hu (1) have seasonal periodic cycles with period around 60 to 80 days from day 100 to 300 . The riverstage and precipitation bears similar periodic behaviors but amplitude spectrum of riverstage is twice smaller than groundwater while that of precipitation is fourth smaller. Nevertheless, the trends of periodic cycles at these two monitoring wells appear to correlate with the trend of river stage 
variation but with some time lags (i.e., region surrounded by black solid line in figure 2). The time lags will be quantified and discussed in the next section.

4.1.2. Selection of Time Period. In order to utilize the information embedded in stream-induced groundwater level variations to characterize the alluvia fan, selection of appropriate periods of the data is necessary. In particular, we are looking for the time interval where the rising and falling of groundwater level at observation wells correlates well with stream stage or flow rate variation while the influence from the precipitation is relatively minor.

Figure 3a and 3b illustrates the maximum wavelet coherence and its associated phase lag of groundwater level and stream stage at the two selected wells: one at 1 and the other $15 \mathrm{~km}$ away from the river during 2010 (Well locations are labeled in square in figure 1a). The warmer color exhibited in the coherence contour plot indicates higher correlation between two variables while the cooler color refers to minor correlation. At high frequencies, such as daily and weekly periods, the groundwater perturbations at these two wells are uncorrelated with the stream stage variation, in spite of their distances to the stream. On the other hand, the seasonal groundwater variations at these two wells between periods of 10 to 60 days are closely related to riverstage fluctuation, especially during the rainfall season (i.e., April to October). This close relationship is exhibited as yellow regions in figure 3, where coherence are larger than 0.8 .

In the most part of the study region, during the rainfall season from late spring to middle of fall, the variation of groundwater level has relative high coherence with the variation of the riverstage with a phase lag around 0.16 cycle (1 to 7 days of time lag), depending on the location of the well. The phase lag is represented by the arrow in 
coherence contour plot. To the contrary, the groundwater level change in responses to the fluctuation of riverstage is not significant during the winter. This may be attributed to the disconnection between riverbed and groundwater table while the unsaturated zone filters out the higher frequency signal.

The coherence between precipitation and groundwater level (Figure 4a and 4b) reveals some similarity with that between stream and groundwater. During the rainfall season, relative high coherence between the rainfall and the groundwater also exists. However, the phase lag of groundwater response is 0.23 cycle (2 to 14 days), which is about twice of that induced by riverstage. The groundwater level change in responses to the fluctuation of rainfall is not significant during the winter and may attribute to the existence of the variably saturated zone.

The coherence analysis shows that seasonal and annual variations of groundwater level correlate well with those of stream stage and flow rate, and precipitation. However, because the lag time of groundwater responses to precipitation fluctuation is about twice longer than that to the stream variation, and the wavelet amplitude spectrum of precipitation is twice smaller than that to the stream variation, the effect of precipitation on groundwater fluctuation within the entire alluvial fan thus can be excluded from the groundwater variation data. Moreover, since long-term groundwater level fluctuations at different wells do not exhibit significant difference in their hydrographs, utilizing annual variation likely will not lead to detailed subsurface heterogeneity than utilizing the seasonal scale variation. For this reason, seasonal variation (Julian day 130-200) during 2010 is utilized to characterize subsurface heterogeneity employed by cross-correlation and SLE approaches in this study. 


\subsection{Spatial Analysis of Groundwater and Riverstage Data}

Maximum cross-correlation values are illustrated in figure $5 a$ between the riverstage at Ziqiang station and groundwater levels at all observation wells, during 2010. The cross-correlation contour map indicates two areas where groundwater level is highly correlated with stream stage variation at Zhuoshui River alluvial fan. The first area locates at the north side of the fan and has highest cross-correlation around 0.7. The second, where the maximum cross-correlation is about 0.7 , locates at the downstream of the Zhuoshui River. Overall, the spatial distribution of the cross-correlation suggests that groundwater fluctuation in the area locates at the northern of the river and the tail of the fan near the river are highly positive correlated with the riverstage variation at the gauging station. In the apex of the alluvial fan, groundwater fluctuations are always negative or uncorrelated with the river variation. Southeast part of the fan is an uncorrelated or small correlated region.

Figure $5 \mathrm{~b}$ is the contour map of time lag of the maximum cross-correlation between groundwater variation at different parts of the aquifer and the riverstage fluctuation at the gauging station. Lag time is the time elapse that the responses of groundwater level at given location lags behind the stream variations. It generally depends on the distance between the groundwater level observation location and the river as well as the aquifer characteristics through which the pressure perturbation induced by riverstage travels. According to this figure, at the apex of the fan, it will take about 15 days for the aquifer to respond to the riverstage perturbation at Ziqiang Bridge. Distinct patterns exist from the apex to the tail and from north to south. The physical explanations for these correlations are discussed in section 4.4.

In summary, at apex of the fan, variation of groundwater level is small, not correlated with variation of stream stage, and lags behind the riverstage fluctuation. 
At the rest of the region, the correlation between stream stage and groundwater level are relative higher with relative shorter lag time. That is, by examining the spatial cross-correlation and time lag contour maps, we may postulate that the apex of the fan has its unique subsurface characteristic, which is significantly different from those at middle and tail of the fan. That is to say, using the stream induced seasonal groundwater level variations at different regions we could possibly map the subsurface characteristics over the alluvial fan.

\subsection{Synthetic Experiment}

To test aforementioned postulation and to assure that the riverstage tomography analysis using field data will lead to meaningful results, we create a synthetic, basin-scale heterogeneous aquifer and simulate its groundwater responses induced by known riverstage fluctuations. These simulated groundwater and river stage data sets are error free, and interference of unknown processes (e.g., pumping events, earthquakes, earth tides, barometric variations, and boundary effects) are excluded. Moreover, aquifer heterogeneity distribution is known precisely. Thus, the hypothesis about the usefulness of the cross-correlation and time lag in terms of mapping heterogeneity can be assessed. Furthermore, the tolerance of the algorism to the white noise can be evaluated.

4.3.1. Synthetic Aquifer. Based on the hydrogeologic map of Zhuoshui River alluvial fan, a two-dimensional horizontal domain of $80 \times 60$ square elements is built. Each element is $1.0 \mathrm{~km} \times 1.0 \mathrm{~km}$. This synthetic aquifer is divided into three zones, consisting of gravels, sands, and clays. This general spatial pattern of sediment distribution is to mimic the one reported by Chang et al. [2015]. Afterward, the detailed spatial $D$ distribution within each zone is generated using a spectral method 
random field generator [Gutjahr, 1989; Robin et al., 1993] with the following statistical characteristics: The mean of $D$ for gravel, sand, and clay are $7.2 \times 10^{11}$, $7.2 \times 10^{7}$, and $7.2 \times 10^{3}\left(\mathrm{~m}^{2} / \mathrm{hr}\right)$, respectively. The variances of $\ln D$ (i.e., natural logarithm of $D$ ) of the corresponding materials are $0.3,1.0$, and 2.2. Notice that the variances of $D$ can be calculated by $\bar{D}^{2}\left[\exp \left(\sigma_{f}{ }^{2}\right)-1\right]$ where $\bar{D}$ represents the mean of $D$ while $\sigma_{f}{ }^{2}$ represents the variance of $\ln D$. The correlation scales for the corresponding materials are 10,25 , and $40(\mathrm{~km})$ for both $\mathrm{x}$ and y directions. These correlation scales are selected to be approximately half of the width of each material zone. Values and spatial distribution of $D$ for all the elements in the synthetic aquifer are shown in figure 6. For the synthetic case with noise considered, white noise with a standard deviation of $0.6 \mathrm{~m}$ were superimposed onto the simulated hydrographs. The average signal-to-noise ratio, defined as the ratio of observed drawdown to standard deviation (known) of the noise, is 0.1 .

The western and eastern boundaries are constant head boundaries to mimic the hydrogologic setting of Zhoushui River alluvial fan. The constant head at the eastern boundary is $120 \mathrm{~m}$ higher than that at the west. Head gradient between headwater and coast is used to mimic the natural regional groundwater flow gradient in the fan. A river is placed through the middle of the fan while another river is at the north. Both of the rivers are treated as prescribed time-varying head boundaries rather than flux boundary used in Yeh et al., [2009] since infiltration fluxes of the real world situation are unknown along the river. The rest of the boundaries are no flow boundary because they are either hills that could be considered as watershed divides between two different basins or relative small streams that has little effect on the groundwater fluctuation. 
In order to simulate river induced groundwater variation, continuous riverstages along Zhuoshui River and Wu River at different times are generated by interpolation of the riverstage records measured from five stream gauge stations (i.e., four at Zhuoshui River and one at Wu River). For Zhuoshui River, because the flood wave propagating from the apex to tail of fan only takes about 8 hours and the distances between gauges are short (only about $10 \mathrm{~km}$ ), the riverstages between every two stream gauges are obtained simply by linear interpolation. For Wu River, because it is a northern boundary only about $10 \mathrm{~km}$ long, the stream stage along the Wu River is simply assumed constant head spatially. These interpolated riverstage temporal and spatial variations are then used as prescribed heads along these rivers in the finite element numerical variable saturated flow model VSAFT2 [Yeh et al., 1993] to simulate groundwater responses.

4.3.2. Cross-Correlation Analysis. Figure 7a displays the result of the cross-correlation analysis, using the synthetic groundwater and riversatge data. It is a contour map of highest cross-correlation between simulated groundwater level variations at different wells and the riverstage fluctuations given at the Zhiqiang Bridge gauging station at downstream of the river. At first glance of the cross-correlation contour map, it apparently captures the general pattern of the reference field (Figure 6). In other words, clusters of high permeability zones are located at similar areas where cross-correlation values are high. Meanwhile, the locations of the low permeable zones correspond to those of the low cross-correlation values. This result reveals that signals of riverstage fluctuations can propagate far distance away from the river; the signals travelling from the river to individual wells are modified by aquifer heterogeneity. These results thus substantiate the theory of hydraulic tomography for characterizing basin-scale heterogeneity, which uses 
riverstage fluctuations as the transmitter and wells as receivers of the signals in geophysical survey terminology.

4.3.3. Estimate of $\boldsymbol{D}$ Spatial Distribution. Following the cross-correlation analysis, the simulated groundwater responses at 65 wells over a period of 70 days are used to conduct the riverstage tomography analysis. Since only riverstage variations are used without knowing the fluxes into the aquifer or hydraulic conductivity values along the river bed, the riverstage tomography can estimate diffusivity (i.e., the ratio of $K$ to Ss) only (see Mao et al., [2013a], Yeh et al., 2015b). This analysis is carried out using SLE, with the known boundary and initial conditions and starting with a uniform mean $D$ value for the entire aquifer, without specifying the spatial distributions of gravel, sand, and clay in the aquifer.

Figure $7 \mathrm{~b}$ illustrates that the estimated high $D$ zones (red) occupy the apex of the fan and region around the northern boundary while the relative low $D$ zones (blue) extend throughout the southern part of alluvial fan. These high and low $D$ patterns are generally consistent with those of the reference field (Figure 6). Noticeably, these patterns are not restricted to the areas closer to the wells or the time varying river boundary where heads were observed and used in the estimation. They also cover areas far away from the wells or near the boundaries of the aquifer. This result indicates that the head at a specific point within an aquifer during the flood event is affected by subsurface hydraulic properties even far away from the observation and near the boundary of the aquifer.

The estimated $D$ values are plotted against the reference $D$ values in figure 7c as a scatter plot. Overall, the estimated pattern is consistent with that of the reference field with bias but the estimated values are scattering largely around the true values. The distribution of the residual variances (uncertainty) of the estimated $D$ (not 
displayed here but has similar pattern with the uncertainty field displayed in figure 10b) shows that the residual variances of the estimates increase as the distance to the monitoring well increases. That is, the shorter the distance between the well or the river, the smaller the uncertainty of the estimate, and the longer the distance, the larger the uncertainty of the estimate. The large scattering of the scatter plot thus is likely due to insufficient number of observed groundwater wells. On the other hand, the unknown trends (the mean value of each zone), which inevitably augment the variance of $D$ to be estimated, may also contribute to the large scattering of the estimate.

Figure 7c also shows that the spatial variance in the reference field is much higher than the spatial variance of the estimated field. Specifically, there are three clusters of data corresponding to the three material types of the reference field. The sand is less biased but not so for clay and gravel. In particular, the $D$ for gravels is underestimated by about two orders of magnitude while for clay is overestimated by about one order.

Based on the above observations, some prior information about the general sand, gravel, and clay zone used as initial starting values of $D$ to riverstage tomography analysis may improve the estimates. The prior information is composed of geometries of gravel, sand, and clay zones, and their corresponding means of the $D$ of the reference field. Figures $8 \mathrm{a}$ and $8 \mathrm{~b}$ display the estimate $D$ fields and the associated scatter plots. As illustrated in these figures, as the prior geological knowledge is used, the bias and errors of the estimates are significantly reduced. The reduction is reflected in slope and $\mathrm{R}^{2}$ of linear regression line between estimate and reference $D$. Compared this case with that without any prior information, the slope increases from 0.66 to 0.98 , indicative of a significant bias reduction. The improvement of the 
estimation reveals that the use of prior information allows the final estimations of each zone reflect the true mean in the reference field and reduces the variability of $D$. This can be also attributed to the fact that during our analysis, only riverstage and groundwater level data are used, and no flux data are available to constrain the estimates, as does hydraulic tomography, where pumping rates are known. The roles of prior geological information on the riverstage tomography agree with the finding shown in Tso et al. [2016], Zhao et al. [2016], and Zhao and Illman [2017].

It should be emphasized that although the overall estimate is improved if the prior information is included, there remain areas where $D$ values are over- or under-estimated. Nonetheless, without data that satisfy the necessary conditions for an inverse problem to be well defined, the best an inverse model can do is to obtain an unbiased estimate field [Yeh et al., 2015a and b].

The tolerance of riverstage tomography to white noise is evaluated using noise contaminated observed hydrographs. The estimated $D$ values are plotted against the reference $D$ values in figure 9. The slopes of both situations (i.e., starting with a uniform $D$ in figure 9 a and distributed $D$ in figure $9 \mathrm{~b}$ ) are similar with those of noise-free cases. The effect of white noise to the estimation of aquifer property is apparently not critical as long as many data points in well hydrographs are used. This is consistent with those findings by Mao et al., [2013b].

\subsection{Application to Zhuoshui River Alluvial Fan}

The next step is to apply riverstage tomography analysis to the field problem, where errors due to measurements, model, and other factors, which are not considered in the model (e.g., effects of unknown pumping, precipitation, and others), are included. That is, we use the interpolated riverstage data and field observed 
groundwater records at all the observation wells in the upper aquifer to estimate $D$ field of the corresponding aquifer. The model setup is identical to that of the synthetic case.

Figure 10a and b illustrates the estimated $D$ field by riverstage tomography and the uncertainty of estimated $D$, respectively. As shown in figure 10a, the estimated $D$ values decrease from the apex to tail of the fan as well as from the north to the south. By comparing figure 10a with figure 5a (cross-correlation contour map) and with the lag time contour map (Figure 5b), we observe that the patterns of the high and low $D$ estimates in figure 10a resemble those of the time lags in figure $5 \mathrm{~b}$ more than those in figure 5a. Figure 10b shows that the uncertainty of the estimated $D$ increase as the distance to the monitoring well increases. That is, we have more confidence on the estimates near the river and the monitoring wells.

Overall, the analysis shows that the apex of the fan has its unique subsurface characteristic. This characteristic is significantly different from those at middle and tail of the fan. As observed in figure 5, in the apex of the alluvial fan, groundwater fluctuations are always negative or uncorrelated with the riverstage variation and lag behind the riverstage about half of a month. While at the other region of the fan, the time lags are essentially less than 5 days with positive correlation. Such a long lag of time at the apex of the fan could be attributed to the sediment texture size and depth of the groundwater table. Based on well logs and geologic survey, the apex mainly consists of coarse gravel while the groundwater table is at $30 \mathrm{~m}$ depth below ground surface. This coarse-textured vadose zone provides a large storage reservoir for the river water (large porosity), and it not only filters out high frequency signals but also delays the response of water table. These reasons seem to support the relative high $D$ zone estimated by riverstage tomography. 
Overall, the application of the riverstage tomography reveals that apex region has relative high $D$ values, while the middle area has intermediate $D$ values, and the tail has relative low $D$ values. Such a spatial $D$ pattern agrees with the well logs and geologic survey, which reports that apex mainly consists of gravel and the middle and tail of the fan are consist of sand and silt/clay.

The result of riverstage tomography analysis also indicates that the subsurface characteristic at northern alluvial fan differs from the southern part as well. The estimated $D$ are relative larger at north than at south. This finding agrees with Chang et al. [2015]'s conclusion. Chang et al. [2015], integrating the well log with electric resistivity survey to investigate this area, found that the northern part of alluvial fan consists of mainly sand with some silt/clay layer along the coast while the southern fan is mainly composed of silt/clay. Such distributions of sediments have been attributed to difference in sediment sources. That is, the southern alluvial fan is mainly deposited by the Beigang River, while the northern fan is deposited by Zhuoshui River. Specifically, Zhuoshui River probably mainly flew through the northern part of the fan in the ancient time. This river is originated from Central Mountain Range, has steeper riverbed gradient and thus great sediment transport capacity. It transports not only sand but also gravel and cobbles, even boulders during large flood events. On the other hand, Beigang River originates from Douliu Hills, which is a smaller hill and has smaller hydraulic gradient. It carries only sediment size smaller than sand [Water Resources Agency, 2014].

Notice that a highly parameterized conceptual model is used in this riverstage tomography analysis. This implies that the $D$ parameter in each element of this model is assumed locally isotropic. In other words, we assume that the element-scale 
anisotropy is not as significant as the spatial variability of $D$ values of each element over the entire alluvial fan.

Finally, the omission of irrigation pumping, precipitation, and other processes and the assumption of a two-dimensional aquifer in the riverstage tomography analysis likely introduce errors in the estimates of true hydraulic parameters in the Zhuoshui River alluvial fan. Our estimates, nevertheless, reflect general heterogeneity trends in the alluvium fan, which are consistent with geology.

\section{CONCLUSION}

Using wavelet analysis, we find that long-term variations in riverstage are correlated well with groundwater level variation over large areas in the alluvium fan under investigation. The cross-correlation analysis of these long-term data yield contour maps of maximum cross-correlation values and time lags. Spatial patterns of these contour maps are similar to patterns of geologic deposits over the alluvium fan. This finding is further substantiated by numerical experiments. That is, groundwater level variations induced by riverstage variations in a synthetic aquifer with known hydraulic property distribution are simulated. Results of the cross-correlation analysis of these simulated data sets show that the spatial patterns of cross-correlation are consistent with the known hydraulic property distribution. This finding implicitly affirms the feasibility of riverstage tomography analysis using SLE, which is built upon the cross-correlation. The synthetic experiments also show that when the geologic zones knowledge is included as prior information for the riverstage tomography analysis, the overall estimate improves. In other words, the prior information about the mean value of each zone reduces the variability of the parameters to be estimated. 
Applications of the riverstage tomography to Zhuoshui River alluvial fan show that the apex of the alluvial fan is a region with relative high $D$, which is likely the main recharge area of the aquifers. $D$ values gradually decrease toward the shoreline of the fan. In addition, $D$ at northern alluvial fan is larger than $D$ at southern. These findings are in agreement with previous geological survey but the riverstage tomography quantifies the $D$ values.

While many assumptions are invoked in this analysis, the results certainly encourage further investigations of the concept of riverstage tomography for characterizing large-scale groundwater basins.

\section{Acknowledgement}

The first, second, and fifth authors would like to acknowledge the support by the Strategic Environmental Research and Development Program (SERDP) (grant ER-1365), Environmental Security, and Technology Certification Program (ESTCP) (grant ER201212) and by the NSF EAR (grant 1014594) from the United State. The second and seventh authors also acknowledge the Outstanding Oversea Professorship award through Jilin University from Department of Education, China, as well as the Global Expert award through Tianjin Normal University from the Thousand Talents Plan of Tianjin City from China. The authors acknowledge the support from Taiwan Typhoon and Flood Research Institute, National Applied Research Laboratories to provide Data Bank for Atmospheric \& Hydrologic Research service from Taiwan. The eighth author acknowledges the Natural Science Foundation of China (grant 51409029). The authors thank associated editor and two anonymous reviewers for their helpful and insightful comments which significantly enhance the quality of this article. 


\section{REFERENCE}

Berg, S.J., and W.A. Illman (2011), Three-dimensional transient hydraulic tomography in a highly heterogeneous glaciofluvial aquifer-aquitard system, Water Resour. Res., 47, W10507, doi:10.1029/2011WR010616.

Berg, S.J., and W.A. Illman (2013), Field study of subsurface heterogeneity with steady-state hydraulic tomography, Ground Water, 51, 29-40, doi:10.1111/j.1745-6584.2012.00914.x.

Berg, S. J., and W. A. Illman (2015), Comparison of hydraulic tomography with traditional methods at a highly heterogeneous site, Ground Water, 53(1), 71-89, doi:10.1111/gwat.12159.

Bohling, G. C., J. J. Butler Jr., X. Zhan, and M. D. Knoll (2007), A field assessment of the value of steady shape hydraulic tomography for characterization of aquifer heterogeneities, Water Resour. Res., 43, W05430, doi:10.1029/2006WR004932.

Cardiff, M., W. Barrash, and P.K. Kitanidis (2012), A field proof-of-concept of aquifer imaging using 3-D transient hydraulic tomography with modular, temporarily-emplaced equipment, Water Resour. Res., 48, W05531, doi:10.1029/2011WR011704. 
Central Geological Survey (1994), The final survey report of the Cho-Shui alluvial fan (in Chinese), Minist. of Econ. Affairs, Taipei, Taiwan.

Central Geological Survey (1999), The hydrogeological survey report of the Cho-Shui alluvial fan (in Chinese), Minist. of Econ. Affairs, Taipei, Taiwan.

Chang P.Y., J.P. Tsai, L.C. Chang, Y.Y. Wu. (2015), From the Conceptual Model to the Apparent Model with Geophysical Non-invasive Measurements: Case Studies in the Choushuichi and Ilan Fan-delta. Presented at the American Geophysical Union Fall Meeting, San Francisco, CA. December 14-18, 2015.

Davis, E. E., K. Wang, K. Becker, and R. E. Thomson (2000), Formation-scale hydraulic and mechanical properties of oceanic crust inferred from pore pressure response to periodic seafloor loading, J. Geophys. Res., 105, 13, 423-435, doi:10.1029/2000JB900084.

Gutjahr, A. L. (1989), Fast Fourier transforms for random field generation, project report for Los Alamos grant, Contract 4-R58-2690R, Dep. Of Math., N. M. Tech., Socorro.

Hao, Y., T.-C. J. Yeh, J. Xiang, W. A. Illman, K. Ando, and K.-C. Hsu (2008), Hydraulic tomography for detecting fracture connectivity, Ground Water, 46(2), 183-192, doi:10.1111/j.1745-6584.2007.00388.x. 
Hsieh, P. A., J. D. Bredehoeft, and S. A. Rojstaczer (1988), Response of well aquifer systems to Earth tides: Problem revisited, Water Resour. Res., 24(3), 468-472, doi:10.1029/WR024i003p00468.

Huang, S.-Y., J.-C. Wen, T.-C. J. Yeh, W. Lu, H.-L. Juan, C.-M. Tseng, J.-H. Lee, and K.-C. Chang (2011), Robustness of joint interpretation of sequential pumping tests: Numerical and field experiments, Water Resour. Res., 47, W10530, doi:10.1029/2011WR010698.

Illman, W. A., X. Liu, and A. Craig (2007), Steady-state hydraulic tomography in a laboratory aquifer with deterministic heterogeneity: Multi-method and multiscale validation of hydraulic conductivity tomograms, J. Hydrol., 341(3-4), 222-234, doi:10.1016/j.jhydrol.2007.05.011.

Illman, W. A., X. Liu, S. Takeuchi, T.-C. J. Yeh, K. Ando, and H. Saegusa (2009), Hydraulic tomography in fractured granite: Mizunami Underground Research site, Japan, Water Resour. Res., 45, W01406, doi:10.1029/2007WR006715.

Jan, C.-D., T.-H. Chen, and H.-M. Huang (2013), Analysis of rainfall-induced quick groundwater-level response by using a Kernel function, Paddy Water Environ., 11, 135-144, doi:10.1007/s10333-011-0299-6.

Li, B., and T.-C. J. Yeh (1998), Sensitivity and moment analyses of head in variably saturated regimes, Adv. Water Res., 21(6), 477-485, doi:10.1016/s0309-1708(97)00011-0. 
Li, B., and T.-C. J. Yeh (1999), Cokriging estimation of the conductivity field under variably saturated flow conditions, Water Resour. Res., 35(12), 3663-3674, doi:10.1029/1999WR900268.

Li, W., A. Englert, O. A. Cirpka, J. Vanderborght, and H. Vereecken (2007a), Two-dimensional characterization of hydraulic heterogeneity by multiple pumping tests, Water Resour. Res., 43, W04433, doi:10.1029/ 2006WR005333.

Li, H., G. Li, J. Cheng, and M. C. Boufadel (2007b), Tide-induced head fluctuations in a confined aquifer with sediment covering its outlet at the sea floor, Water Resour. Res., 43, W03404, doi:10.1029/2005WR004724.

Lin, Y.-B., Y.-C. Tan, T.-C. J. Yeh, C.-W. Liu, and C.-H. Chen (2004), A viscoelastic model for groundwater level changes in the Cho-Shui River alluvial fan after the Chi-Chi earthquake in Taiwan, Water Resour. Res., 40, W04213, doi:10.1029/2003WR002412.

Liu, S., T.-C. J. Yeh, and R. Gardiner (2002), Effectiveness of hydraulic tomography: Sandbox experiments, Water Resour. Res., 38(4), 1034, doi:10.1029/2001WR000338.

Liu, X., W. A. Illman, A. J. Craig, J. Zhu, and T.-C. J. Yeh (2007), Laboratory sandbox validation of transient hydraulic tomography, Water Resour. Res., 43, W05404, doi:10.1029/2006WR005144. 
Lu, Z., and V. V. Vesselinov (2015), Analytical sensitivity analysis of transient groundwater flow in a bounded model domain using the adjoint method, Water Resour. Res., 51, doi:10.1002/2014WR016819.

Mao, D., T.-C. J. Yeh, L. Wan, K.-C. Hsu, C.-H. Lee, and J.-C. Wen (2013a), Necessary conditions for inverse modeling of flow through variably saturated porous media, Adv. Water Resour., 52, 50-61, doi:10.1016/j.advwatres.2012.08.001.

Mao, D., T.-C. J. Yeh, L. Wan, J.-C. Wen, W. Lu, C.-H. Lee, and K.-C. Hsu (2013b), Joint interpretation of sequential pumping tests in unconfined aquifers, Water Resour. Res., 49, 1782-1796, doi:10.1002/wrcr.20129.

Misiti, M., Y. Misiti, G. Oppenheim, J.-M. Poggi (2007), Wavelets and their Applications, Wiley Press, ISBN: 9781905209316

Robin, M. J. L., A. L. Gutjahr, E. A. Sudicky, and J. L. Wilson (1993), Cross-correlated random field generation with the direct Fourier transform method, Water Resour. Res., 29, 2385-2397, doi:10.1029/93WR00386.

Rojstaczer, S. (1988), Determination of fluid flow properties from the response of water levels in wells to atmospheric loading, Water Resour. Res., 24(11), 1927-1938, doi:10.1029/WR024i011p01927. 
Rojstaczer, S., and F. S. Riley (1990), Response of the water level in a well to Earth tides and atmospheric loading under unconfined conditions, Water Resour. Res., 26(8), 1803-1817, doi: 10.1029/WR026i008p01803.

Straface, S., T.-C. J. Yeh, J. Zhu, S. Troisi, and C. H. Lee (2007), Sequential aquifer tests at a well field, Montalto Uffugo Scalo, Italy, Water Resour. Res., 43, W07432, doi:10.1029/2006WR005287.

Tso, C.-H. M., Y. Zha, T.-C. J. Yeh, and J.-C. Wen (2016), The relative importance of head, flux, and prior information in hydraulic tomography analysis, Water Resour. Res., 52, 3-20, doi:10.1002/2015WR017191.

Vesselinov, V. V., S. P. Neuman, and W. A. Illman (2001), Three-dimensional numerical inversion of pneumatic cross-hole tests in unsaturated fractured tuff: 2. Equivalent parameters, high-resolution stochastic imaging and scale effects, Water Resour. Res., 37(12), 3019-3042, doi:10.1029/ 2000WR000135.

Water Resources Agency (2014), Planning groundwater recharge with coupled numerical models of surface and subsurface water (in Chinese), Minist. of Econ. Affairs, Taipei, Taiwan.

Yeh, T.-C. J., R. Srivastava, A. Guzman, and T. Harter (1993), A Numerical Model for Water Flow and Chemical Transport in Variably Saturated Porous Media, Ground Water, 31, 634-644, doi:10.1111/j.1745-6584.1993.tb00597.x 
Yeh, T.-C. J., M. Jin, and S. Hanna (1996), An Iterative Stochastic Inverse Method: Conditional Effective Transmissivity and Hydraulic Head Fields, Water Resour. Res., 32(1), 85-92, doi:10.1029/95WR02869.

Yeh, T.-C. J., and S. Liu (2000), Hydraulic tomography: Development of a new aquifer test method, Water Resour. Res., 36(8), 2095-2105, doi:10.1029/2000WR900114.

Yeh T.-C. J., C.-H. Lee, K.-C. Hsu, W. A. Illman, W. Barrash, X. Cai, J. Daniels, E. Sudicky, L. Wan, G. Li, C. L. Winter (2008), A view toward the future of subsurface characterization: CAT scanning groundwater basins, Water Resour. Res., 44, W03301, doi:10.1029/2007WR006375.

Yeh, T.-C. J., J. Xiang, R. M. Suribhatla, K.-C. Hsu, C.-H. Lee, and J.-C. Wen (2009), Riverstage tomography: A new approach for characterizing groundwater basins, Water Resour. Res., 45, W05409, doi:10.1029/2008WR007233.

Yeh, T.-C. J., R. K., and K. C. Carroll (2015a), Flow through Heterogeneous Geologic Media, Cambridge Press, ISBN: 9781107076136

Yeh, T.-C. J., D. Mao, Y. Zha, J.-C. Wen, L. Wan, K.-C. Hsu, C.-H. Lee (2015b), Uniqueness, scale, and resolution issues in groundwater model parameter identification, Water Sci. Eng., 8, 175-194, doi: 10.1016/j.wse.2015.08.002. 
Zha, Y., T.-C. J. Yeh, D. Mao, J. Yang, W. Lu (2014), Usefulness of flux measurements during hydraulic tomographic survey for mapping hydraulic conductivity distribution in a fractured medium, Adv. Water Resour., 71, 162-176, doi: 10.1016/j.advwatres.2014.06.008.

Zha, Y., T.-C. J. Yeh, W. A. Illman, T. Tanaka, P. Bruines, H. Onoe, H. Saegusa (2015), What does hydraulic tomography tell us about fractured geological media? A field study and synthetic experiments, J. Hydrol., 531, 17-30, doi: 10.1016/j.jhydrol.2015.06.013.

Zhang, J., and T.-C. J. Yeh (1997), An iterative geostatistical inverse method for steady flow, Water Resour. Res., 33, 63-71, doi: 10.1029/96WR02589.

Zhao, Z., W. A. Illman, and S. J. Berg (2016), On the importance of geological data for hydraulic tomography analysis: Laboratory sandbox study, J. Hydrol., 542, 156-171, doi: 10.1016/j.jhydrol.2016.08.061.

Zhao, Z, and W. A. Illman (2017), On the importance of geological data for three-dimensional steady state hydraulic tomography at a highly heterogeneous aquifer-aquitard system, J. Hydrol., 544, doi: 640-657, 10.1016/j.jhydrol.2016.12.004.

Zhu, J., and T.-C. J. Yeh (2005), Characterization of aquifer heterogeneity using transient hydraulic tomography, Water Resour. Res., 41, W07028, doi:10.1029/2004WR003790. 
Zhu, J., and T.-C. J. Yeh (2006), Analysis of hydraulic tomography using temporal moments of drawdown recovery data, Water Resour. Res., 42, W02403, doi:10.1029/2005WR004309. 
a)

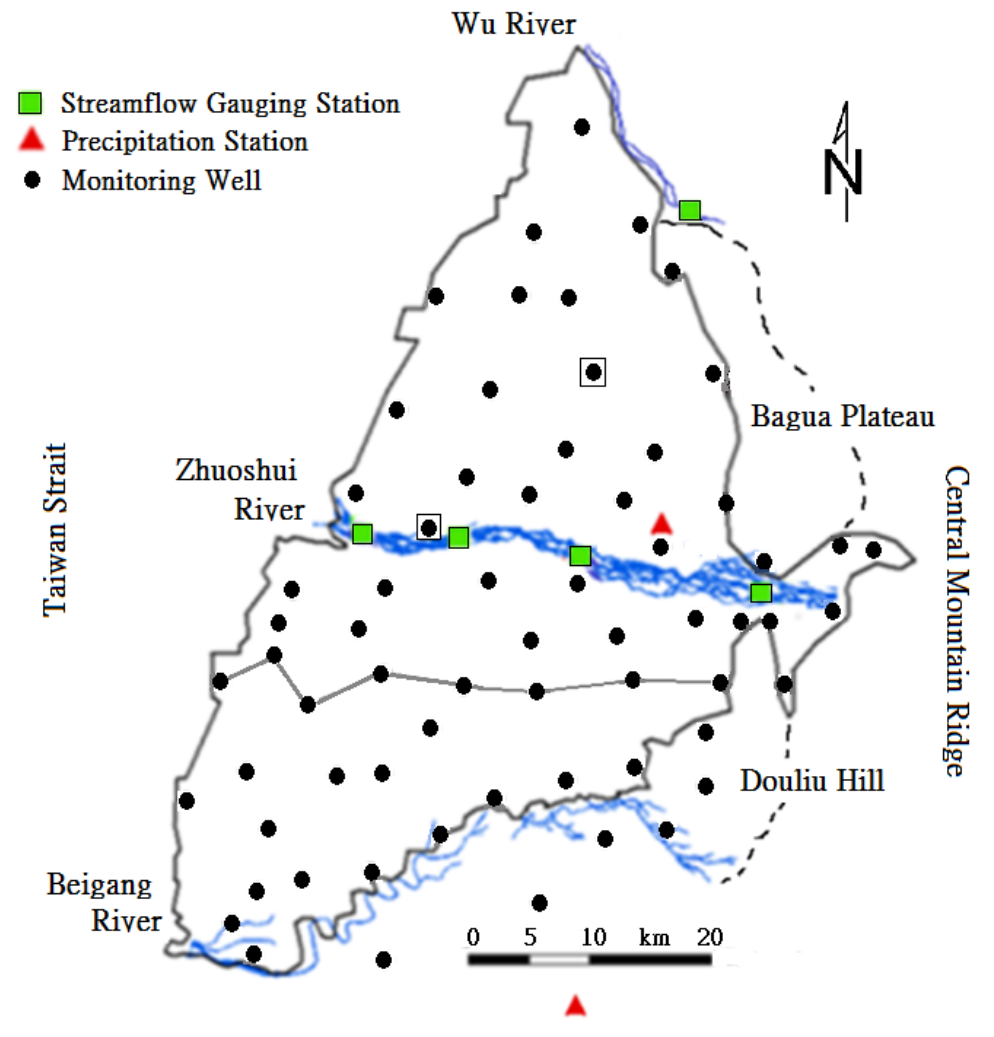

b)

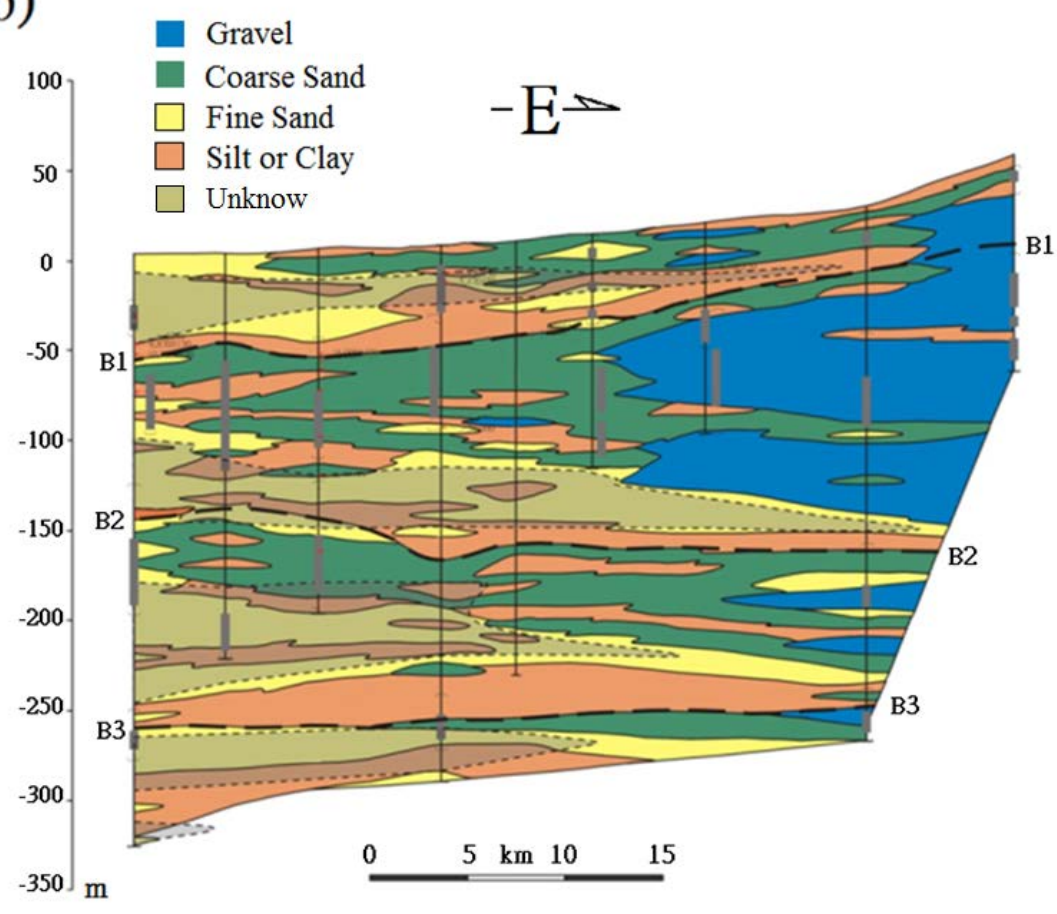




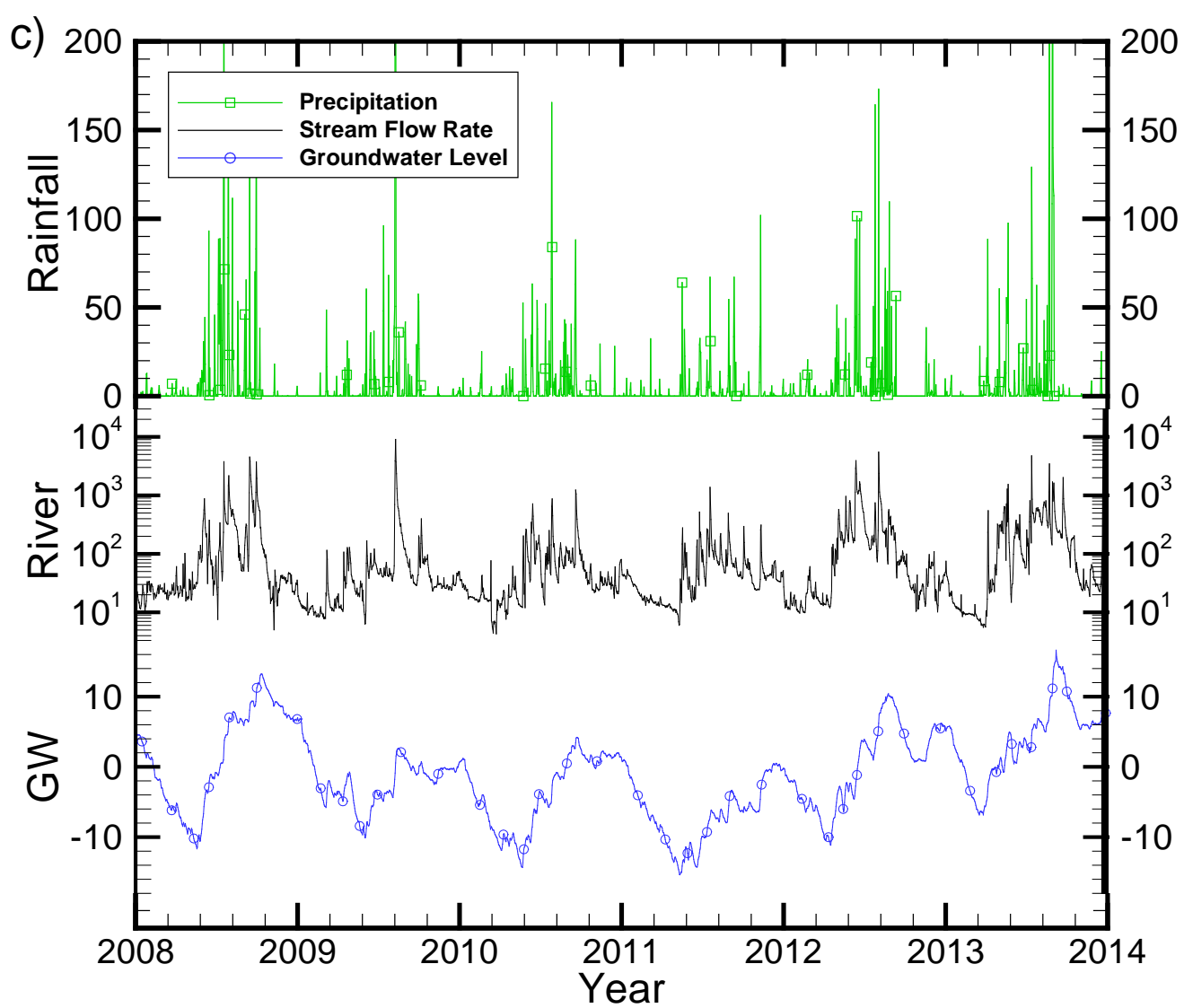

Figure 1. a) Locations of wells (black circles), precipitation stations (red triangles), and river gauging stations (green squares). The river gauging stations, from upstream to downstream, are Zhangyun Bridge, Xizhou Bridge, Ziqiang Bridge, and Xibin Bridge, respectively. The precipitation station located at apex of the fan is Xiashuipu while the one below the scale is Chiayi station. The black circles with square are the groundwater monitoring wells 1 and $15 \mathrm{~km}$ away from the river, namely, Tan-Cian (1-1) and Si-Hu (1) stations, respectively. b) The geological cross section along the solid black line in figure 1a. Blue, green, yellow, and orange zones in the cross section represent gravel, coarse sand, fine sand, and silt/clay, respectively. The labels B1, B2, and B3 in the geological cross section roughly indicate the bottom 
of each aquifer. c) Long term precipitation (mm/day) at Chiayi station, stream flow rate $\left(\mathrm{m}^{3} / \mathrm{s}\right)$ at Ziqiang Bridge, and average groundwater level (m) during 2008 to 2014 . 

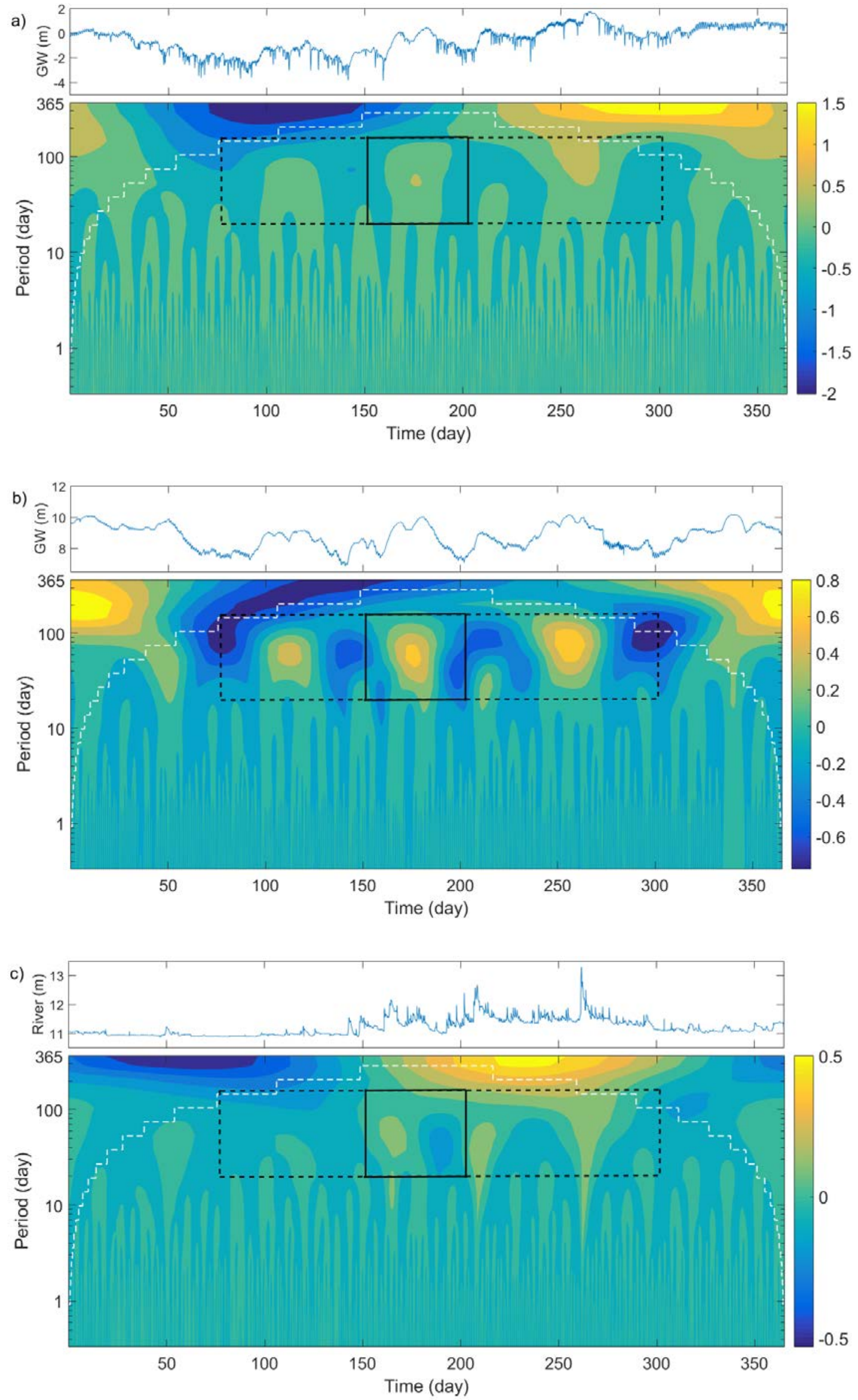
Figure 2. Time series and associated wavelet amplitude spectrograms of the a) groundwater level at Tan-Cian (1-1), b) Si-Hu (1), c) riverstage at Ziqiang Bridge during 2010. The contour color represents the real part of wavelet coefficient. The white dash line represents the influence of the limited length of data to the precision of estimated wavelet spectrum. Features bounded by the black solid and dash lines are discussed in section 4.1.1. 

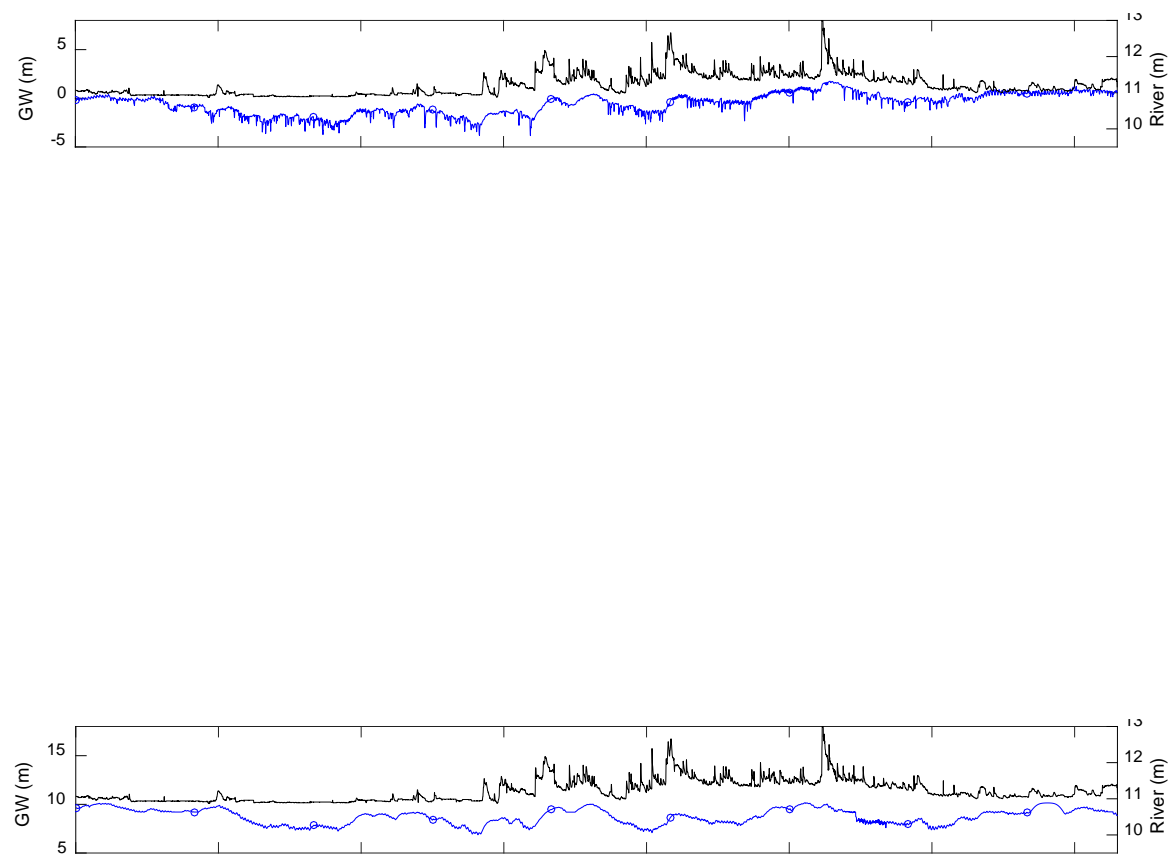

Figure 3. a) Riverstage time series (black line) at Ziqiang Bridge and groundwater time series (blue line with circle) from well Tan-Cian (1-1) as well as wavelet coherence between the groundwater and the riverstage series. The rise of arrows indicates delay in groundwater response. The rise angle from the horizon is the phase lag with unit in cycle. The values in the region above the white dash line are uncertain due to the limited length of the time series. b) is the same as a) but the groundwater time series is from well Si-Hu (1). 

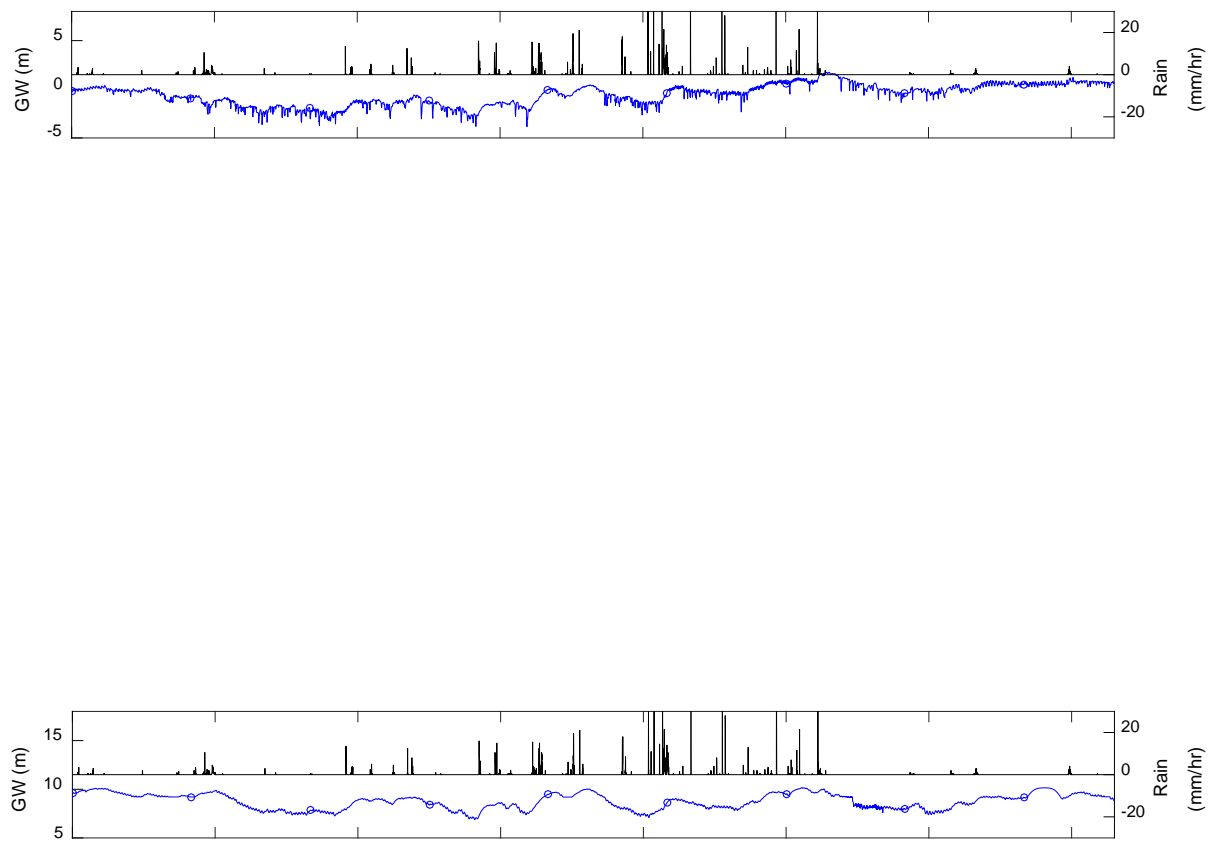

Figure 4. a) Precipitation time series (black line) at Xiashuipu and groundwater time series (blue line with circle) from well Tan-Cian (1-1) as well as wavelet coherence between the groundwater and the precipitation series. The rise of arrows indicates delay in groundwater response. The rise angle from the horizon is the phase lag with unit in cycle. The values in the region above the white dash line are uncertain due to the limited length of the time series. b) is the same as a) but the groundwater time series is from well Si-Hu (1). 


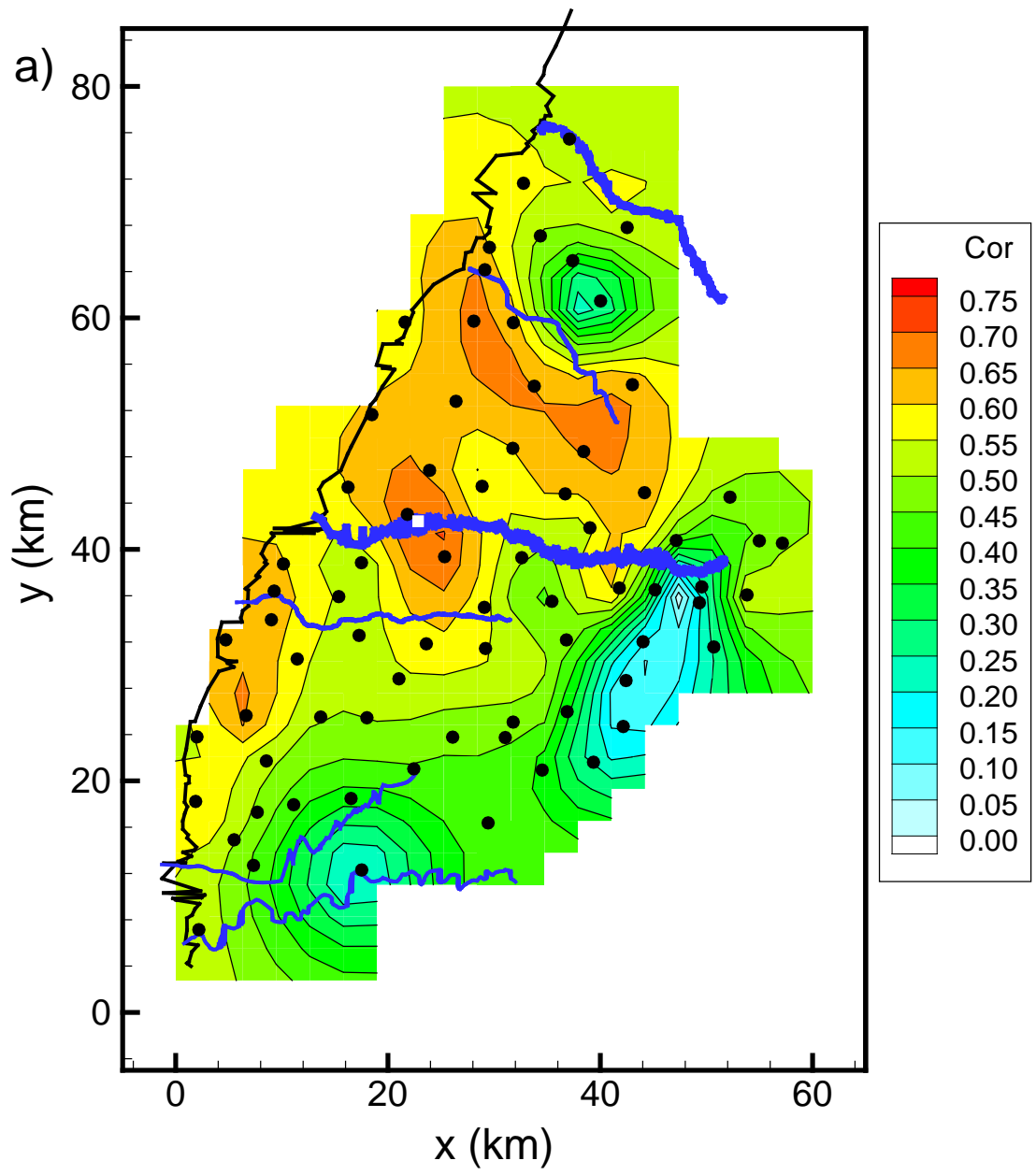




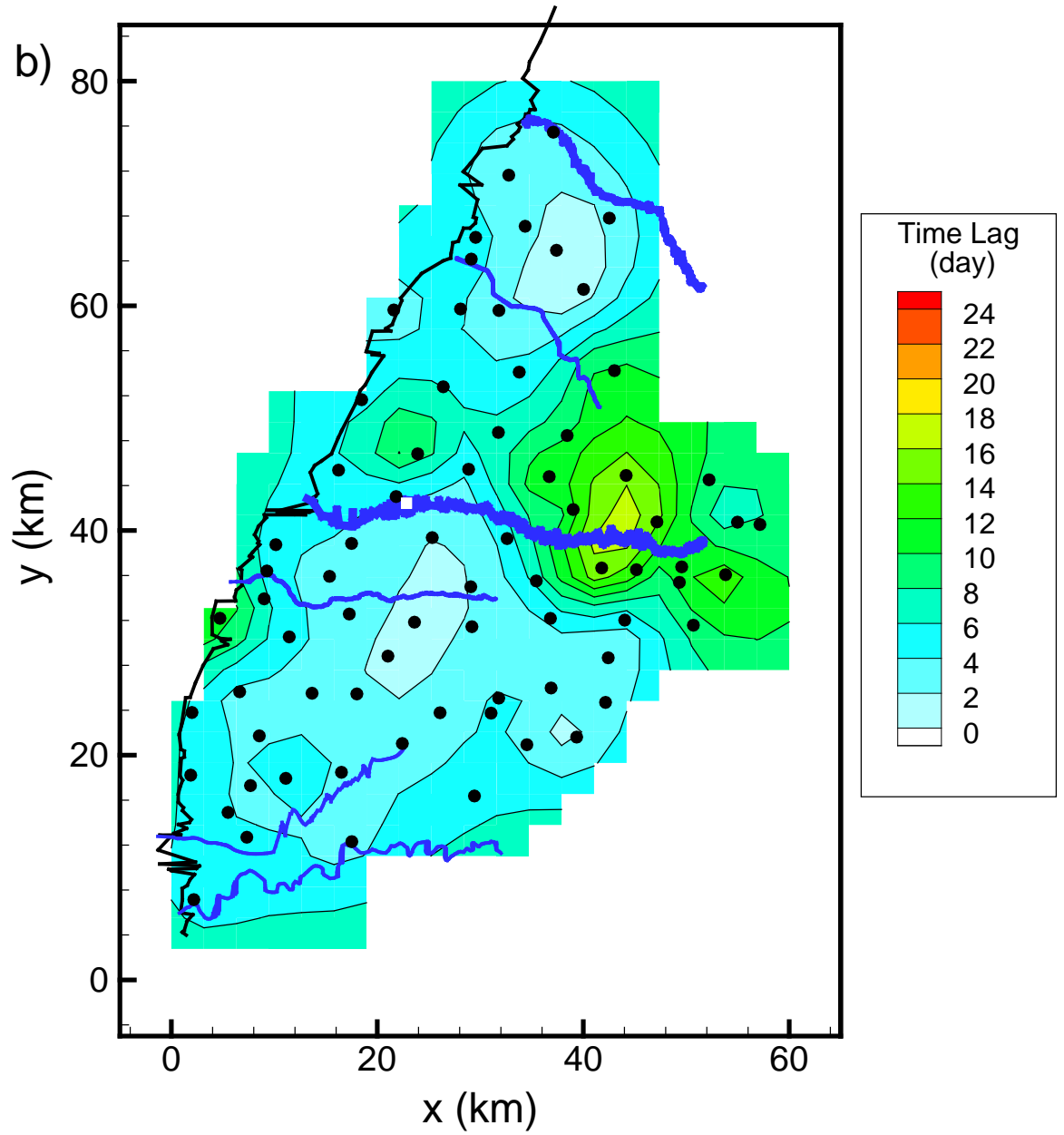

Figure 5. Contour maps of a) maximum cross-correlation and b) time lag between groundwater level and the seasonal river stage variation during Julian day 130-200 at Ziqiang Bridge (the white square). 


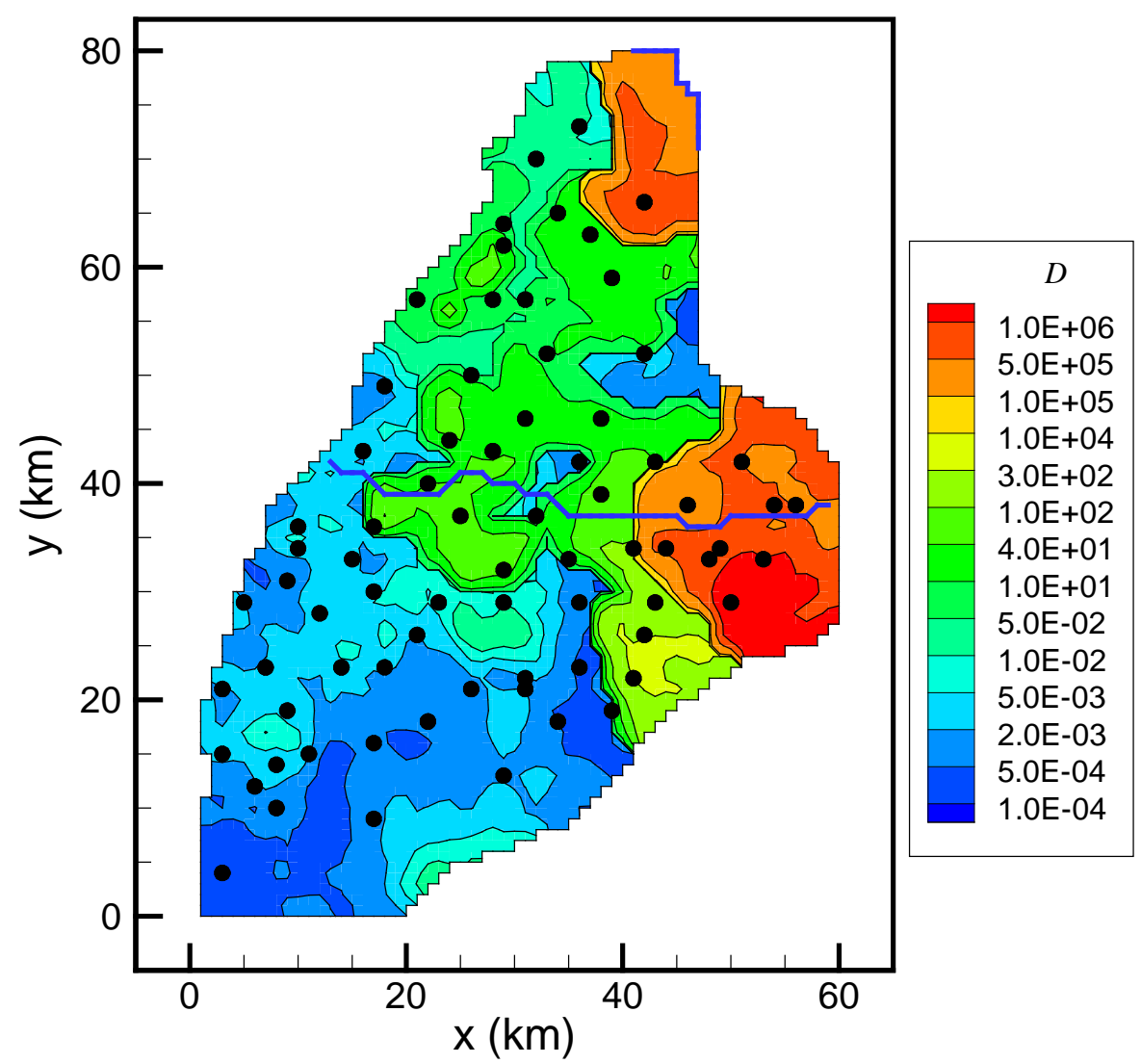

Figure 6. Reference $D\left(\mathrm{~km}^{2} / \mathrm{hr}\right)$ field. Spatial distributions of gravel (red), sand (green), and clay (blue) of the synthetic aquifer. Dark circles represent locations of the observation wells, and blue lines represent stream while the rest represents constant head boundaries. 


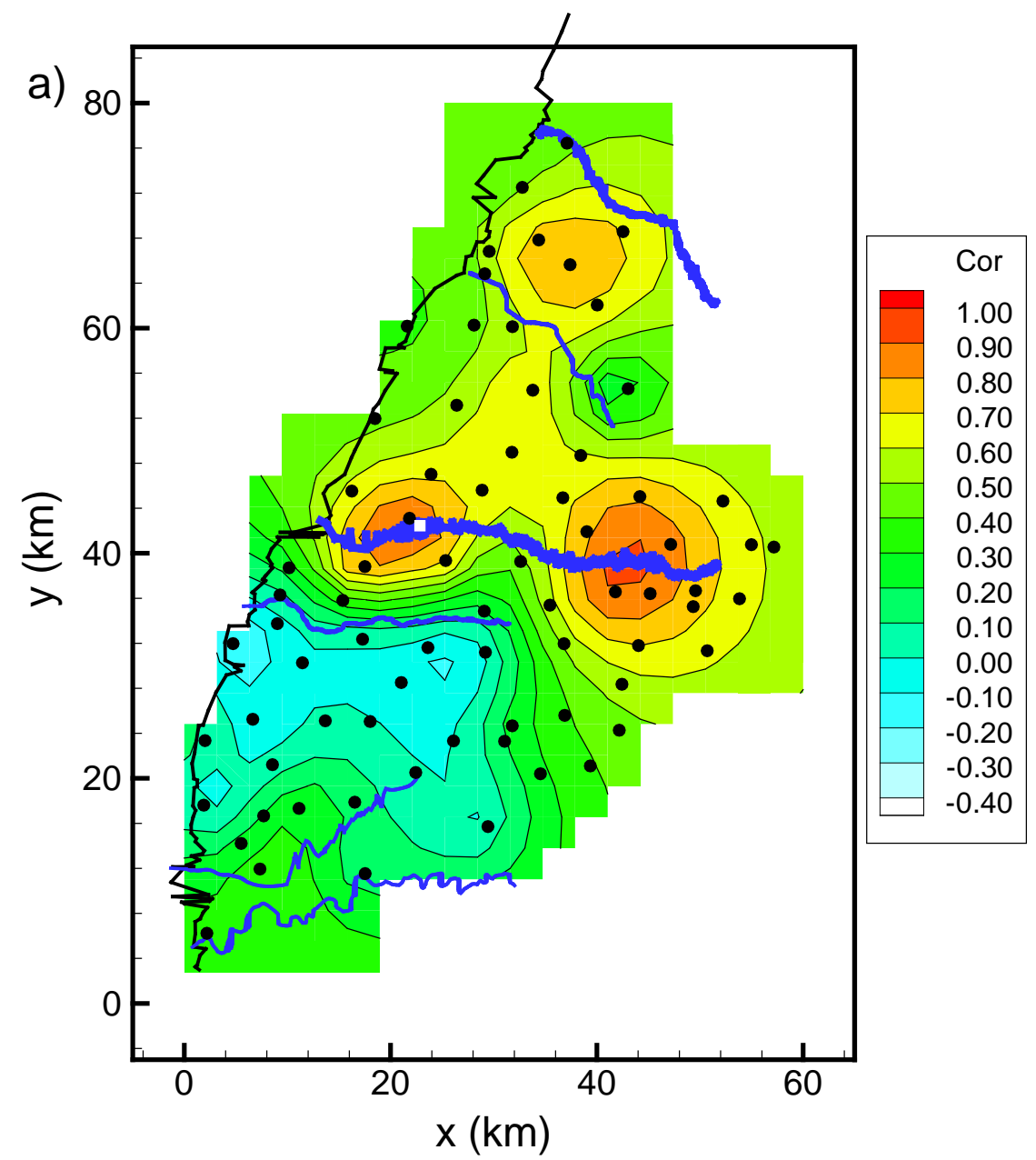




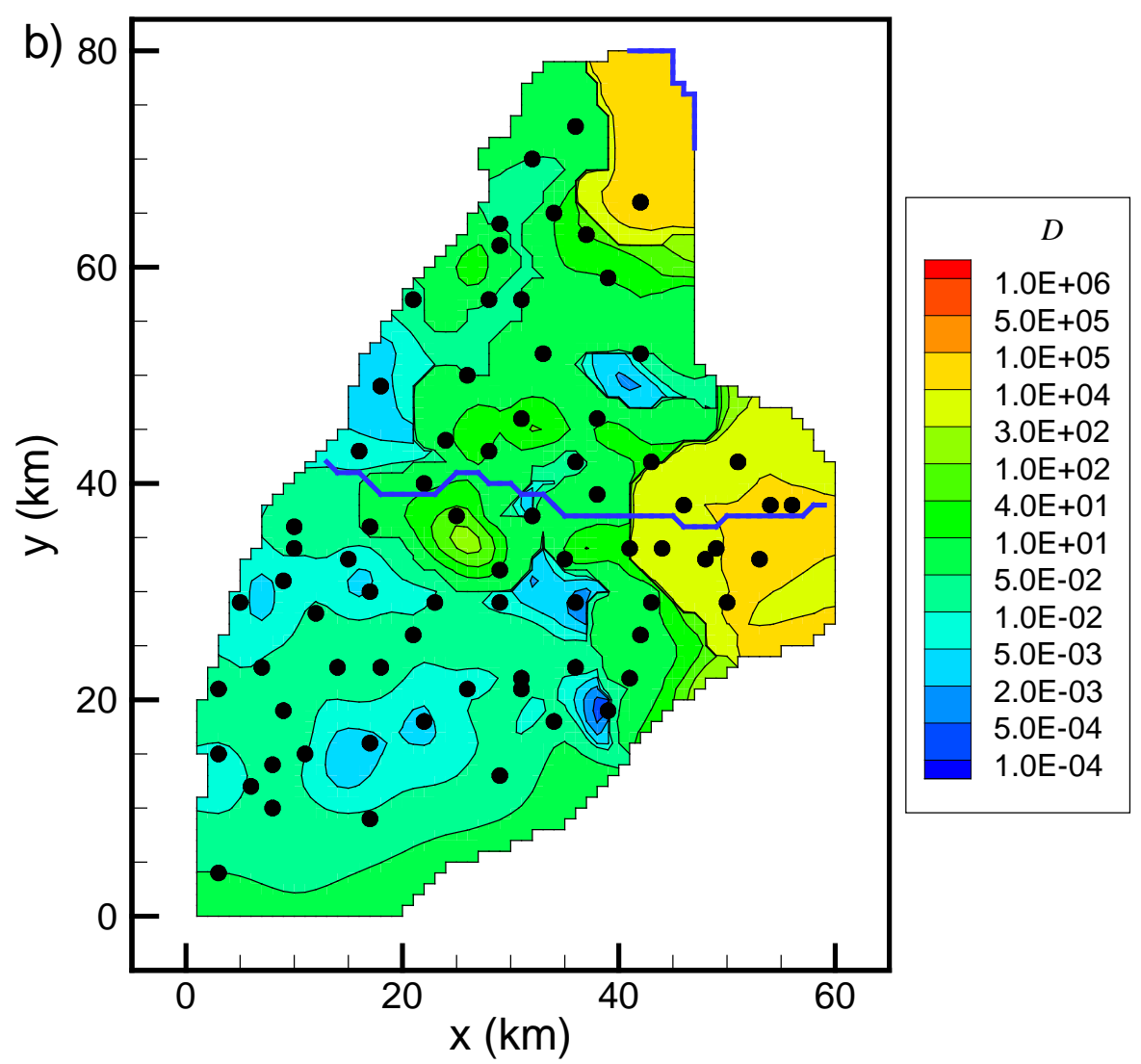




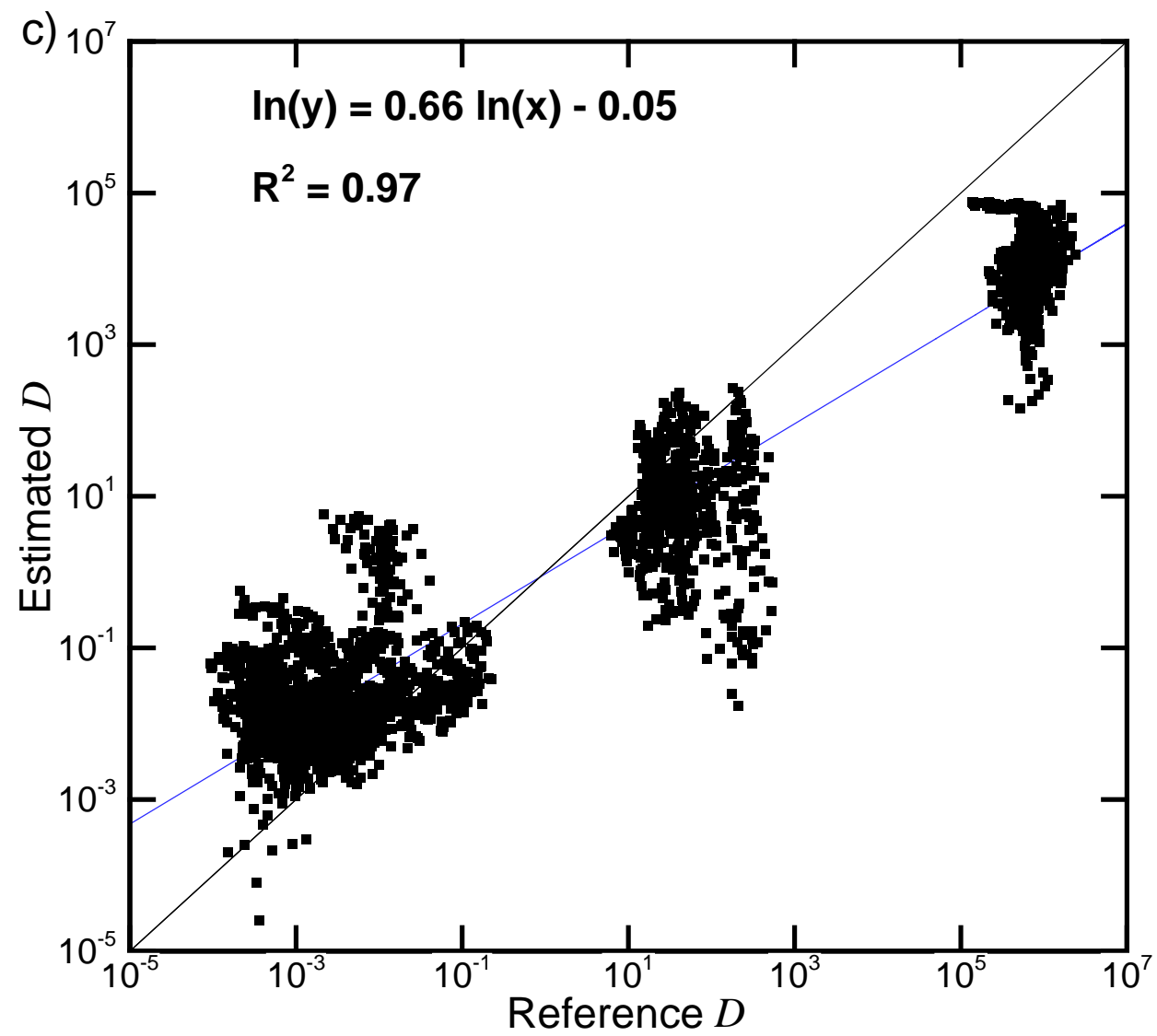

Figure 7. a) Cross-correlation contour map, b) Estimated hydraulic diffusivity $\left(\mathrm{km}^{2} / \mathrm{hr}\right)$ fields and c) scatter plot of reference versus estimated $D$ starting from uniform mean. These fields are estimated from noise noise-free signals. 


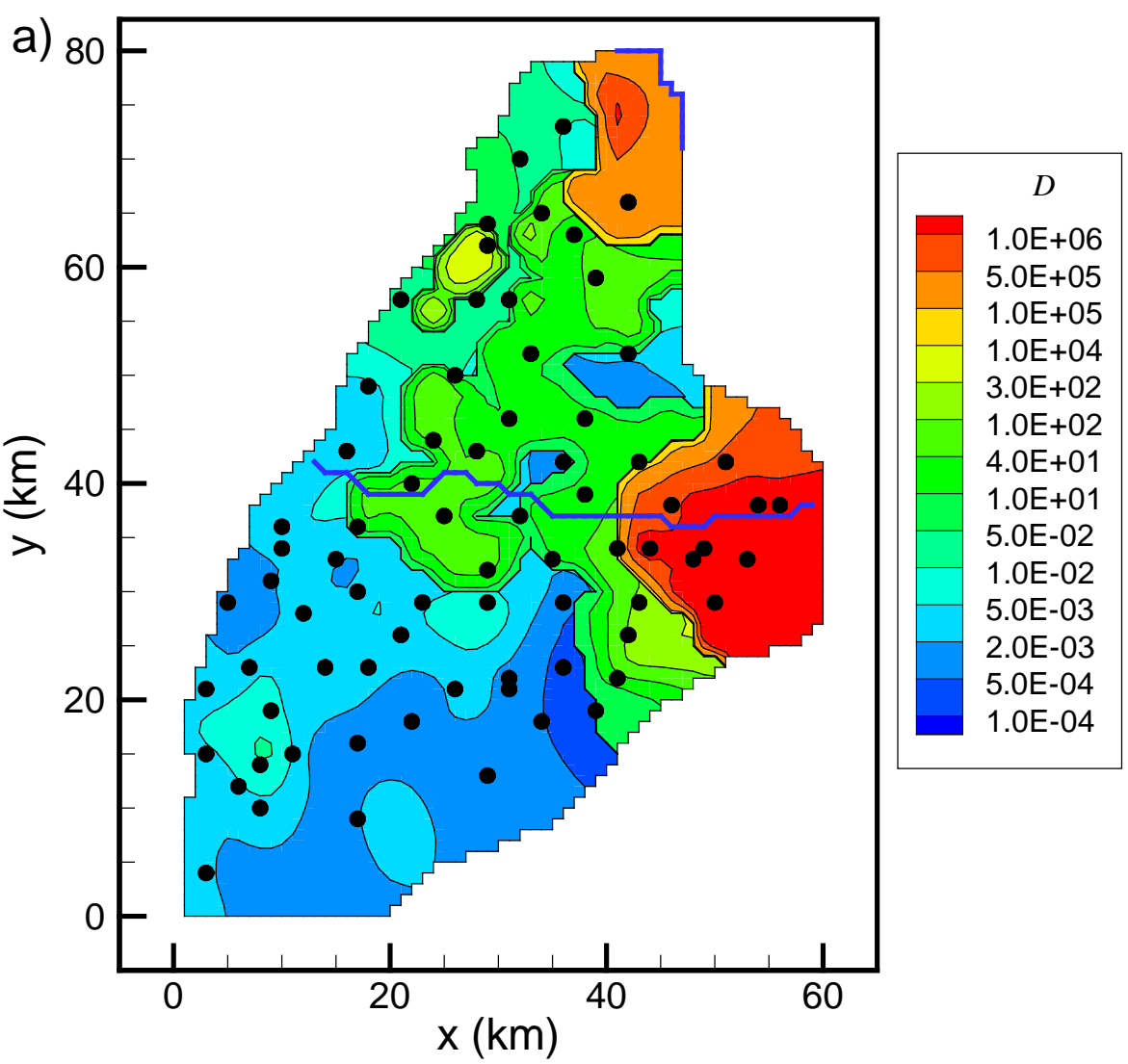




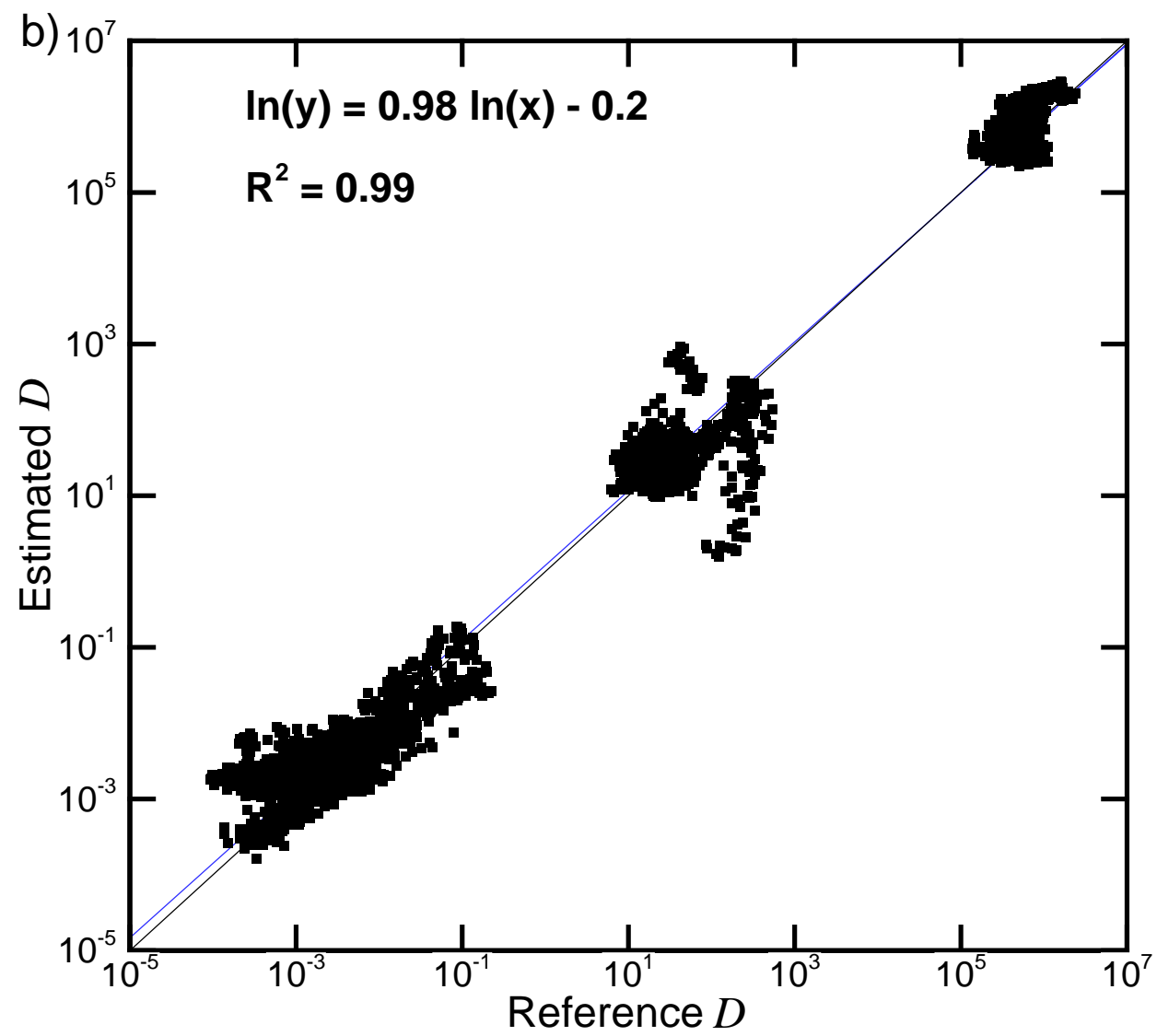

Figure 8. a) Estimated hydraulic diffusivity $\left(\mathrm{km}^{2} / \mathrm{hr}\right)$ fields and b) scatter plot of reference versus estimated value starting from true distributed mean without noise. 

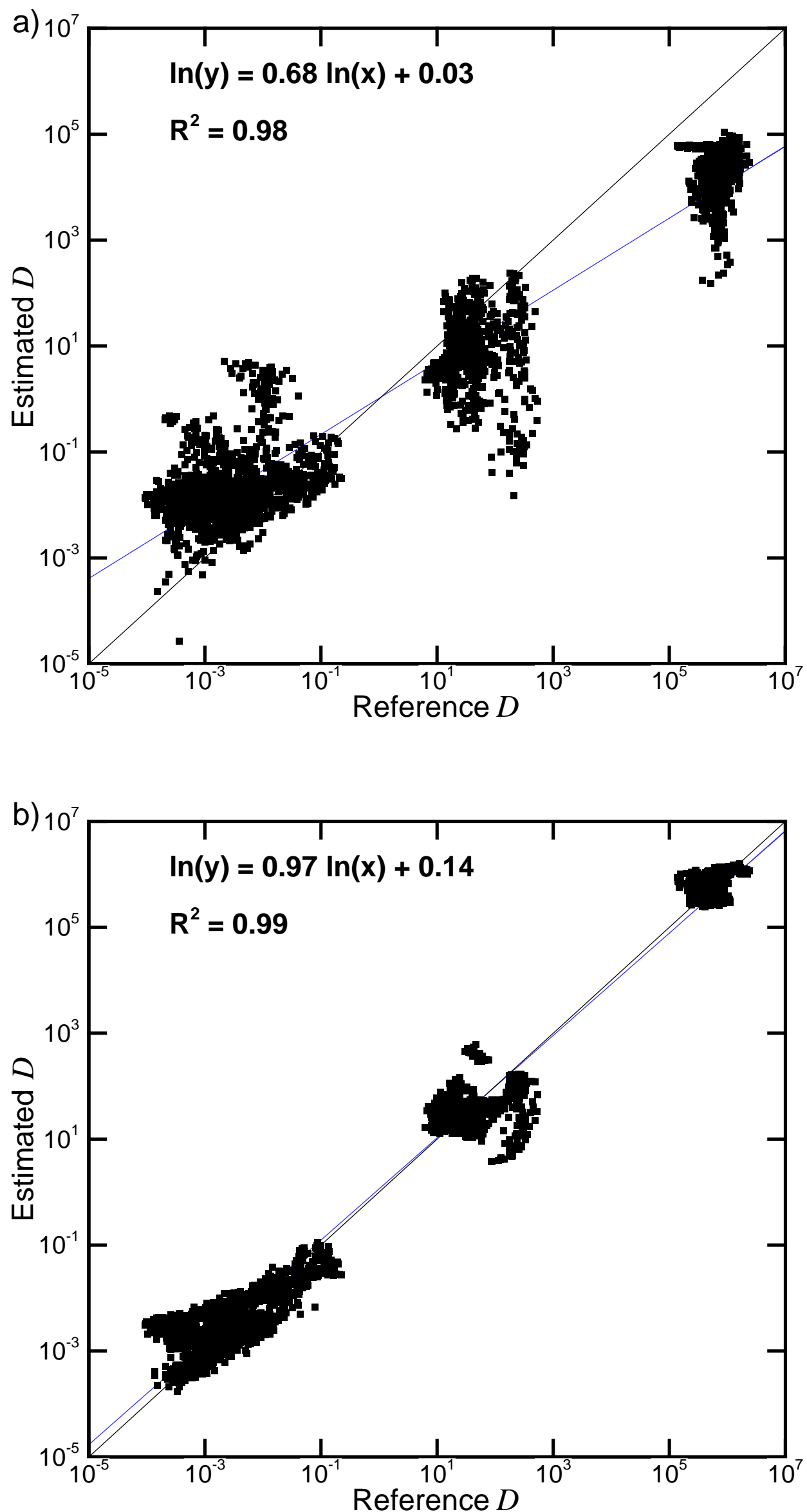
Figure 9. Scatter plots of reference versus estimated $D$ starting from a) uniform mean and b) true distributed mean. The diffusivity field is estimated utilizing noisy signals. 

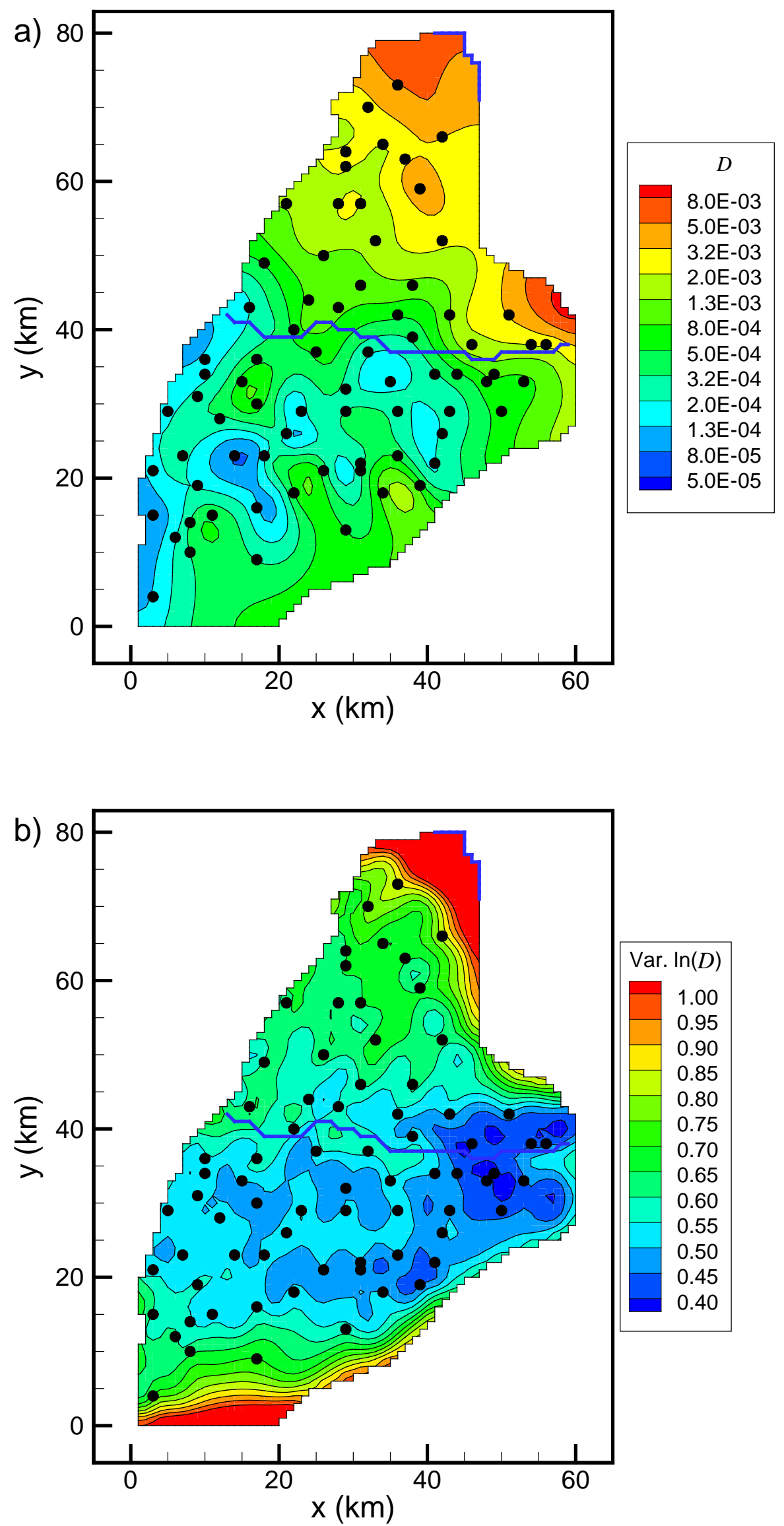
Figure 10. a) Estimated hydraulic diffusivity $\left(\mathrm{km}^{2} / \mathrm{hr}\right)$ fields. b) Uncertainty of diffusivity estimation. 